VATT Working Papers 132

\title{
Discrete Labor Supply: Empirical Evidence and Implications
}

Tuomas Kosonen

Tuomas Matikka 


\title{
VATT WORKING PAPERS
}

\section{2}

Discrete Labor Supply: Empirical Evidence and Implications

\author{
Tuomas Kosonen \\ Tuomas Matikka
}


Tuomas Kosonen: Labour Institute for Economic Research (Helsinki, Finland), Academy of Finland and CESifo, tuomas.kosonen@labour.fi

Tuomas Matikka: VATT Institute for Economic Research (Helsinki, Finland), Academy of Finland and CESifo, tuomas.matikka@vatt.fi

Acknowledgments: We would like to thank Richard Blundell, Raj Chetty, Alexander Gelber, Jarkko Harju, Ohto Kanninen, Patrick Kline, Tuomas Pekkarinen, Wojciech Kopczuk, Tomi Kyyrä, Jukka Pirttilä, Jim Poterba, Emmanuel Saez, Matti Sarvimäki, Joel Slemrod, Marko Terviö, Mazhar Waseem, Danny Yagan and Gabriel Zucman as well as participants in numerous conferences and seminars for their helpful comments and discussions. We are also grateful to Spencer Bastani for helping us to get started with the simulation model. Funding from the Academy of Finland (No. 303689) is gratefully acknowledged. Matikka acknowledges funding from the Academy of Finland (No. 322074).

ISBN 978-952-274-254-4 (PDF)

ISSN 1798-0291 (PDF)

URN:ISBN:978-952-274-254-4

Valtion taloudellinen tutkimuskeskus

VATT Institute for Economic Research

Arkadiankatu 7, 00100 Helsinki, Finland

Helsinki, May 2020 


\title{
Discrete Labor Supply: \\ Empirical Evidence and Implications
}

\author{
Tuomas Kosonen and Tuomas Matikka*
}

May 15, 2020

\begin{abstract}
We provide novel evidence of discrete labor supply responses to tax incentives and study the broader implications of discrete rather than continuous labor supply. We utilize an income notch and a reform that shifted the location of the notch in order to study the labor supply mechanisms. We find transparent evidence of discrete labor supply responses, revealing that wage earners even in the part-time labor market can face significant restrictions in their available labor supply choices. As an implication of discrete labor supply, we show that the conventional differencesin-differences and bunching elasticity estimates can be downward-biased when labor supply is discrete.
\end{abstract}

Keywords: labor supply; discrete choices; tax elasticity

JEL Classification Codes: H21, H24, J22

Acknowledgments: We would like to thank Richard Blundell, Raj Chetty, Alexander Gelber, Jarkko Harju, Ohto Kanninen, Patrick Kline, Tuomas Pekkarinen, Wojciech Kopczuk, Tomi Kyyrä, Jukka Pirttilä, Jim Poterba, Emmanuel Saez, Matti Sarvimäki, Joel Slemrod, Marko Terviö, Mazhar Waseem, Danny Yagan and Gabriel Zucman as well as participants in numerous conferences and seminars for their helpful comments and discussions. We are also grateful to Spencer Bastani for helping us to get started with the simulation model. Funding from the Academy of Finland (No. 303689) is gratefully acknowledged.

* Kosonen: Labour Institute for Economic Research (Helsinki, Finland), Academy of Finland and CESifo, tuomas.kosonen@labour.fi. Matikka: VATT Institute for Economic Research (Helsinki, Finland), Academy of Finland and CESifo, tuomas.matikka@vatt.fi. 


\section{Introduction}

Analyzing labor supply is one of the most important topics in labor economics, public finance and macroeconomics. A central part of this work has been devoted to understanding how labor supply responds to various policies, for example how income taxation affects labor supply decisions. Textbook models often assume that labor supply choices are flexible and continuous because these models are designed to be simple, tractable and easy to implement empirically, contrary to what discrete labor supply models would be. However, many real-life labor supply responses tend to be discrete rather than continuous, such as switching between jobs or choosing between part-time or full-time work. Consequently, the choice between continuous and discrete models is a subject that has been debated for quite some time in economics (see e.g. Dickens and Lundberg 1993 and Blundell et al. 2008). Beyond theoretical and structural considerations, this choice may have important consequences for quantitative analysis. However, the previous literature has not extensively analyzed the consequences of continuous versus discrete labor supply for the magnitude of the welfare losses or accuracy of reduced-form estimation methods.

This paper provides novel and transparent evidence of discrete labor supply responses among wage earners, and shows that this feature has major implications for observed labor supply responses to policy. We utilize a reform that shifted the location of an income notch, allowing us to separate between continuous and discrete labor supply responses to tax incentives. We then show with our simulation model that discrete labor supply responses lead to a potential downward-bias in the reduced-form elasticity of taxable income estimates, and also can reduce the true welfare impact of tax policies.

This paper makes a number of contributions to the literature. First, we provide causal and transparent reduced-form evidence of discrete labor supply responses. There is an extensive literature on discrete labor supply, which is mostly theoretical or empirical but structural, and thus quasi-experimental evidence on discrete labor supply is scarce (Dickens and Lundberg, 1993; van Soest, 1995; Saez, 1999; Saez, 2002; Blundell et al., 2008; Kreiner et al., 2015).

Second, we contribute to the literature analyzing optimization frictions. These are 
defined as factors of labor supply that are outside of the canonical continuous-choice model, such as adjustment costs, optimization errors or inattention, and by definition include also discrete labor supply (Chetty et al., 2011; Chetty, 2012; Kleven and Waseem, 2013; Søgaard, 2019; Gelber et al., 2020). The previous literature finds that adjustment costs attenuate labor supply responses and thus the observed elasticity of taxable income (ETI). As an example, Chetty et al. (2011) find that search frictions reduce switching from a current job to another, but otherwise labor supply is continuous in their analysis. We show that continuous and discrete labor supply have crucially different welfare implications: the observed ETI represents the sufficient statistic for welfare analysis under discrete labor supply choices but not under temporary optimization frictions analyzed in the earlier literature. Moreover, the discrete labor supply could be an important reason for why the true elasticity of taxable income could be low, although not always.

Third, we contribute to the extensive literature estimating ETI with reduced-form methods such as differences-in-differences (Gruber and Saez, 2002) or bunching (Saez, 2010; Kleven and Waseem, 2013) by showing that these methods can produce estimates that are significantly downward-biased when labor supply responses are discrete instead of continuous. As ETI is a key measure for welfare losses caused by income taxes (Chetty, 2009a; Saez et al., 2012), the downward bias would lead to an assessment that these welfare losses are smaller than what they actually are.

Our empirical analysis in more detail utilizes a combination of an income notch, i.e. a jump in the average tax rate creating strong local tax incentives, and a reform that shifted out the location of the notch. The institutional setting involves a monthly study subsidy for Finnish higher education students. A university student loses eligibility for one month of the subsidy (approximately 500 euros) if her annual earnings exceed a predetermined gross income threshold (9200 euros before 2008), causing a sharp drop in disposable income. As Finnish university students typically participate in flexible parttime labor markets during their studies, this notch creates a real constraint affecting the labor supply choices for a majority of students. In 2008, the location of the threshold was increased by $30 \%$, allowing students to earn more income before they lose the subsidy 
they are eligible for.

We examine the impact of the reform on the whole income distribution. This allows us to observe whether the notch also affected earnings further away from the threshold, which is revealing for different labor supply mechanisms as argued below. To capture the causal impact of the relocation of the notch, we develop a novel method in the spirit of differences-in-differences method. We calculate the change in the relative density of the students' income distribution associated with the reform and contrast it to changes in the distribution of a control group consisting of non-student young wage earners who are similar to students in their labor market behavior and earnings. In this way we also extend the standard bunching method to estimate the broader changes in the distribution of the treatment and control groups. The changes in the density are measured using a wide income range below the notch rather than a region just below it as in the bunching method. Moreover, we measure the change in the density by the changes in the shape of the distribution associated with the reform, while in the standard bunching method the excess mass is calculated by relating the observed shape of distribution to a counterfactual density estimated from the surrounding distribution ${ }^{1}$

As our main empirical result we find that the change in the location of the notch caused distinctive earnings responses from a broad income range for students, but we find no discernible changes in the income distribution of the control group. Many students who were located far below the old notch before the reform significantly increased their earnings precisely at the time when the location of the threshold was increased. Thus the overall shape of the earnings distribution changed due to the reform, evident in that the density at lower incomes reduced, and consequently increased at higher income levels. Because we do not find changes in the income distribution of the control group, it is not credible that the earnings responses of students would have arisen from other contemporary changes in the part-time labor market in Finland. Also, the income dis-

\footnotetext{
${ }^{1}$ Our approach is similar in nature to other methods used to analyze changes in distributions (see e.g. Athey and Imbens 2006 and Firpo et al. 2009). However, by extending the methods used in the bunching approach, we can more feasibly relate our estimates to those derived using the bunching method, which has been predominantly used to analyze earnings responses to local discontinuities in incentives such as tax rate kinks and notches (see Kleven 2016).
} 
tribution of students remained practically unchanged in the period before and after the reform, which further supports the notion that the shifting of the distribution was caused by the reform to study subsidy income thresholds.

In addition, extensive register-based panel data enable us to follow the same students over time and link their earnings to the characteristics of the firm they worked for, allowing us to shed more light on the mechanisms at play. The results utilizing the panel dimension show that large and discrete earnings increases were much more common at the time of the reform compared to the period before it. At the time of the reform, students originally below the income threshold had about a 10\% probability of increasing their annual earnings by $50 \%$ or more, whereas in the years before the reform this probability was constantly only $5 \%$. This and other similar results further support the notion that the earnings responses within a broad income range arise because of individual-level earnings relocation responses and not, for example, by participation of more productive students to the labor markets after the reform.

In order to understand the mechanisms explaining our empirical results, we contrast the predictions from discrete and continuous labor supply models and show that our results are only consistent with the discrete labor supply model. Our result, that a substantial fraction of students that who were initially located far below the notch in income distribution responded to the shifting out of the notch, is not consistent with the continuous labor supply model. In that model these individuals are unaffected by the reform, because they have already optimized their earnings location and neither their abilities, preferences nor budget sets change, when the notch shifts out. This argument applies to all continuous models even when augmented with adjustment costs or optimization errors. Instead, in the discrete labor supply model an individual considers multiple but sparse earnings locations in the income distribution. An individual located below the notch compares her utility in the chosen earnings location to the surrounding available locations. If a location at a higher income level beyond the notch becomes more attractive after the relocation of the notch, the individual responds to the reform with a large increase in her earnings by switching to this new location. With heterogeneous 
individuals, a fraction increases their earnings leading to an overall shift in the earnings distribution. This is exactly what we observe in our empirical analysis. Therefore, our empirical results show that discreteness is an essential component of models analyzing labor supply, as analyzed by a number of previous studies (Dickens and Lundberg, 1993; van Soest, 1995; Saez, 1999; Saez, 2002; Kreiner et al., 2015).

We find further empirical support for the hypothesis that labor supply is discrete by examining the responses of two specific subgroups of students: those who work in arguably more discrete labor markets (public sector, or research, manufacturing and construction in the private sector) and those working in less discrete labor markets (restaurants, bars and cafes, hotels, cleaning and security services). The latter group faces less discrete labor markets because they typically have more flexible working hours and are more likely subject to hourly rather than monthly wages compared to the first group. We find a significantly larger shift in the earnings distribution from below the original notch for students who work in the more discrete labor markets. Furthermore, the distinctive discrete labor supply responses among students provide evidence of mechanisms that are likely to be applicable more broadly in the labor force, as typical labor markets feature even more discreteness than those where students work 2

We apply a novel method we developed to estimate the earnings elasticity with respect to taxes when labor supply is discrete that uses the relocation of the income notch as exogenous variation. When labor supply is discrete, an appropriate elasticity concept is mobility elasticity, which measures earnings responses across discrete earnings locations as a response to a change in the average tax rates across these locations (Saez, 2002; Kreiner et al., 2015). In contrast, when labor supply is continuous, we would apply the standard ETI formula, where we apply a change in marginal tax rate only to those who are affected by the change based on their pre-reform earnings location.

In our method to estimate the mobility elasticity, we relate changes in log earnings across the whole income distribution due to the reform to the changes in the average tax rates. The benefit of this approach is that it captures all the responses created by

\footnotetext{
${ }^{2}$ This argument about discreteness applies even though the underlying preferences determining responsiveness to incentives might be different among students compared to other wage earners.
} 
the reform and relates them to a theoretically meaningful change in tax incentives in the discrete choice framework. We provide an estimate of 0.18 for the mobility elasticity, which is close to earlier earnings elasticity estimates in the literature (see Saez et al. (2012) for a survey) and also close to what Søgaard (2019) finds for university students in Denmark who face a similar income threshold involving a kink instead of a notch. However, if we had instead used the standard bunching method presented in Kleven and Waseem (2013) to estimate the elasticity utilizing the local excess mass relative to the surrounding stationary income distribution just below the notch, we would have estimated a significantly smaller elasticity of 0.07 . The bias in the bunching estimate arises from the fact that this method cannot capture those responding to a local incentive beyond its immediate surroundings, which we identify utilizing the threshold reform. In general, our analysis illustrates that the definition of a treatment group and construction of a counterfactual need to be reconsidered in the standard bunching method when earnings responses are discrete.

Moreover, we build a simulation model calibrated to the observed responses of students to illustrate the impact of discrete versus continuous labor supply on reduced-form income elasticity estimates. To keep the analysis tractable, we simulate a simple tax reform where an increase in the marginal tax rate from $40 \%$ to $60 \%$ above a predetermined kink point is repealed, representing a tax rate cut for higher incomes. We then apply the standard ETI estimator based on a differences-in-differences method that, for example, Gruber and Saez (2002) use in their seminal paper, as well as our mobility elasticity estimator that produces unbiased estimates. We find that the standard elasticity estimator could produce a significant downward bias depending on how taxpayers are assigned into treatment and control groups. The bias occurs when those who do not face a tax rate change based on their pre-reform earnings are assigned into the control group, but these individuals could nevertheless respond to the reform when earnings choices are discrete. In our baseline simulation, the mobility elasticity estimate is almost twice as large as the biased ETI estimate (0.177 vs. 0.098). Another source of bias in the standard estimates stems from the tax rates used in the estimator because they differ under the continuous 
and discrete labor supply models.

Furthermore, discreteness of labor supply affects the magnitude of the unbiased true ETI. In our baseline simulation calibrated to match our empirical data, the true elasticity is smaller in the discrete than in the continuous model by a factor of more than two. Contrary to this, Kreiner et al. (2015) find that the elasticity might be larger in the long run than in short run in their discrete job-search model, which resembles our discrete labor supply model. The mechanism Kreiner et al. (2015) emphasize is that with a discrete set of alternative choices individuals respond by making larger jumps in their earnings when they switch between jobs compared to a continuous model. Our simulations are in line with this but also show that a significant fraction of individuals do not respond to changes in tax incentives at all because of a larger distance between available earnings locations in the discrete model. Thus the average labor supply response could be either larger or smaller under the discrete as compared to the continuous model depending on which of the mechanisms dominate. In our simulation calibrated to match our empirical data the latter effect dominates. More broadly, this finding suggests that discrete labor supply provides a feasible explanation of why most previous studies tend to find small or modest ETI estimates and also why the estimates differ under various institutional contexts (see Saez et al. 2012 and Neisser 2019).

Finally, the tax elasticity under discrete labor supply relates to the discussion on the welfare implications of taxes in the optimization frictions literature (Chetty, 2009a; Chetty, 2012). In the static discrete labor supply model the observed mobility elasticity estimate represents the sufficient statistic for welfare analysis. In contrast, in a model where labor supply is constrained by temporary adjustment frictions, such as inattention, low tax salience and optimization errors, the empirically observed elasticity is smaller than the underlying structural elasticity, and is therefore not the sufficient statistic for welfare analysis (Chetty et al., 2009; Chetty et al., 2011; Chetty, 2012; Chetty et al., 2013; Chetty and Saez, 2013; Kleven and Waseem, 2013; Søgaard, 2019; Gelber et al., 2020). Therefore, the distinction between the mechanism analyzed in this paper and those in earlier studies is that they entail different welfare implications. However, empirically 
both mechanisms may be important in explaining observed labor supply and earnings responses to taxes.

This paper proceeds as follows: Section 2 presents the relevant institutions and empirical methods. Section 3 presents the empirical results. In Section 4 we discuss the theoretical mechanisms, and Section 5 presents our simulation results and discusses the broader implications of discrete labor supply. Section 6 concludes.

\section{Institutions, data and empirical methods}

\subsection{Study subsidy for university students}

In Finland, all students who are enrolled in a university or polytechnic can apply for a monthly-based study subsidy, administered nationally by the Social Insurance Institution of Finland (hereafter SII). The subsidy is intended to enhance equal opportunities in acquiring higher education, and to provide income support for students who often have low disposable incomes. In Finland, university education is publicly provided and there are no tuition fees. A large proportion of individuals receive higher education in Finland (approximately $40 \%$ of individuals aged 25-34 have a degree), and the study subsidy program is widely used among students.

The maximum amount of the subsidy was 461 euros per month in 2007. The default number of subsidy months per year is 9 , which a large proportion of students also choose. The eligibility for the study subsidy depends on personal annual gross income (labor income + capital income), and an academic criterion of completing a certain predefined number of credit points per academic year. Parental income or wealth do not affect eligibility nor the amount of the benefit for students not living with their parents.3

The discontinuity in labor supply incentives is created by an income threshold. If a student has annual gross income higher than a predetermined threshold, the study

\footnotetext{
${ }^{3}$ The full study subsidy includes a study grant and a housing benefit. The standard study grant was $259 € /$ month and the maximum housing benefit $202 € /$ month in the academic year $2006 / 2007$. Housing benefits are granted only for rental apartments, and the housing allowance is reduced if spousal gross income exceeded 15,200 per year (in 2007). In addition to the study subsidy, students can apply for repayable student loans which are secured by central government.
} 
subsidy of one month is reclaimed by the SII. This results in an increase in the effective average tax rate, or an increase in the implied marginal tax rate of over $100 \%$, in a region just above the threshold, creating a notch in the budget set of students. With the default 9 months of the subsidy that most students take, the income threshold was at 9260 euros in 2007. An additional month of the subsidy was reclaimed for an additional 1010 euros of income above the threshold. This implies that the schedule ultimately comprises multiple notches. Students can deviate from the default of 9 months and alter the number of subsidy months by application, or by returning already granted subsidies by the end of March in the next calendar year. Having more study subsidy months reduces the income threshold, and vice versa..$^{4}$

The study subsidy program was reformed in 2008. In the reform the income threshold was increased by approximately 30\%. For a typical student with 9 study subsidy months, the annual income threshold increased from 9260 to 12,070 euros. In addition, the monthly study subsidy was increased slightly from 461 to 500 euros per month. Other details of the system were not changed, including the academic criterion related to the required number of academic credits. ${ }^{5}$

Figure 1 illustrates the study subsidy schedule before and after 2008 for a student who collects the default 9 subsidy months. First, the figure shows that students face large local incentives not to exceed the income threshold. Once the income threshold is exceeded, losing one month of the subsidy causes a significant dip in disposable income. Therefore, the notch created by the study subsidy induces a strictly dominated region just above the threshold where students can earn more disposable income by reducing their gross earnings. Furthermore, the figure underlines the distinctive change in incentives caused by the increase in the location of the income threshold in 2008, highlighting that the reform encouraged students to increasing their earnings above the old income threshold. Finally, Table A1 in Appendix A shows the income thresholds in numbers before and

\footnotetext{
${ }^{4}$ In 2007, the formula for the annual income threshold was the following: 505 euros per study subsidy month and 1515 euros per month without the study subsidy, plus a fixed amount of 170 euros.

${ }^{5}$ As with the old regime, an additional month of the subsidy is reclaimed after an additional 1310 euros of gross income above the threshold. After 2008, the formula for the threshold was the following: 660 euros per study subsidy month and 1970 euros per month when no study subsidies are collected, plus a fixed amount of 220 euros.
} 
after 2008, and presents the relative loss in disposable income incurred if the income threshold was exceeded.

\subsection{Data and descriptive statistics}

Although the majority of students have access to the study subsidy and repayable student loans, most university students in Finland also work part-time during their studies within and between semesters. Therefore, the means-testing of the study subsidy creates a real constraint affecting the labor supply choices for a majority of students. In our analysis, we use panel data on all working-age individuals (15-70 years) living in Finland in 1999-2013, provided by Statistics Finland. These data include a variety of registerbased variables, such as detailed information on tax register and social benefit items, including information on the study subsidy program. With these data, we can analyze responses to the incentives created by the program and learn how various individual characteristics affect labor supply responses.

Table 1 shows the descriptive statistics for students in 1999-2013. In our analysis, we drop first-year students and students who graduate within a given year in order to avoid the effects of potential income shocks before studies and after graduation. However, dropping first-year students and graduates does not affect the main results in any meaningful way. Mean annual labor income among our sample of students is 8446 euros. We observe that $80 \%$ of students earned more than 500 euros of labor income in a year. In addition, only $55 \%$ of students received labor earnings from only one employer, indicating that students tend to work in different types of jobs during the year. These observations indicate that many students work in part-time or temporary jobs during their studies and breaks between semesters in order to increase their disposable income and/or to gain work experience while studying. In terms of sectors, $19 \%$ of students work in manufacturing including construction, $16 \%$ in hospitality services such as hotels and restaurants, $39 \%$ in administrative and support services or in the public sector, and $25 \%$ in other sectors including those whose sector cannot be identified in the data. In terms of study fields, $17 \%$ of students in our sample study arts and humanities, $19 \%$ business 
and social sciences, $34 \%$ technology or health and social services and $29 \%$ in other fields including those whose field of study cannot be identified.

In our baseline analysis, we focus on students who received 9 months of study subsidy before and after 2008. For this group, the income threshold increased from 9260 to 12,020 euros. The advantage we gain by fixing the number of subsidy months is that we can isolate the effect of the change in the location of the threshold on the earnings distribution for a large part of the student population. This restriction is, however, not very selective as a large proportion of students receive 9 months of the study subsidy, partly because it is the default choice and partly because it presumably creates a good balance between subsidies and labor earnings for many students. The share of students receiving the default subsidy months is $42.4 \%$. Furthermore, students who receive the default subsidy are very similar to the overall student population, except that they are on average slightly younger (22.4) and have less labor income (5633 euros) than all students. Nevertheless, we also test the robustness of our results by including students who deviate from the default subsidy choice.

\subsection{Estimation}

The 2008 reform that shifted the location of the income threshold creates a unique empirical set-up to study earnings responses to a distinctive and salient change in tax incentives. We are particularly interested in investigating whether local tax incentives, such as notches or kinks, affect income distributions further away from the local discontinuity in incentives. Thus we examine the shape and location of the whole income distribution before and after the reform, and develop a new method to estimate these changes building on differences-in-differences and bunching methods. These allow us to observe whether the notch also affects earnings further away from the threshold, revealing the existence of potential constraints that limit the possibility to continuously adjust labor supply which we discuss in detail below. Without the reform we could not identify those in the income distribution who are affected by the notch but are located far away from it.

Labor supply responses to a local discontinuity in the budget set can be estimated 
with the increasingly popular bunching method (see Kleven (2016) for a survey). In the bunching method, labor supply is captured through labor earnings z. Earnings respond to an income notch at an earnings level $z^{*}$. The magnitude of the response is estimated by relating the observed excess mass in the earnings distribution within an income range $\left[z_{L}, z^{*}\right]$ just below the notch to a counterfactual density that would exist in the absence of the discontinuity. Typically, the counterfactual density is estimated by fitting a flexible polynomial function to the observed earnings distribution, but excluding an income range around the threshold. Graph (a) in Figure 2 illustrates a hypothetical distribution with bunching below a tax notch. We present the standard bunching method in more detail in Appendix B.

However, the bunching method produces downward-biased earnings response estimates if the threshold affects the earnings distribution more broadly than just around the local discontinuity. We explain in detail in Section 4 that discrete labor supply would produce such wider responses. Then, the bias in the bunching method can arise from two factors. First, local earnings responses just below the notch $\left[z_{L}, z^{*}\right]$ underestimate the extent of the true responses. The responses from a wider income range could remain undetected if they do not produce a clearly visible excess mass that is clearly distinguishable from the shape of the surrounding income distribution. Second, the surrounding density outside the bunching region cannot be used to estimate a credible counterfactual describing the shape of the distribution in the absence of a local discontinuity, because the shape of the distribution is potentially affected by changes in the distribution from a wider income range.

We take the idea of the bunching method but apply it to detect broader responses in the earnings distribution we identify using the reform that shifts out the location of the local discontinuity. Also, we follow a differences-in-differences (DiD) method to estimate the counterfactual change in the distribution using the changes in the income distribution of a control group, as detailed below. Graph (b) in Figure 2 illustrates these broader changes in an earnings distribution that we aim to estimate. We exploit the 2008 reform and use the pre-2008 earnings distribution to identify the extent of the response. 
We set the lower limit $z_{L}$ well below the old threshold, reflecting the broader changes in earnings in the distribution. We denote the distributions relative to the total number of students in the distribution in order to take into account the fact that the number of students at certain income levels might slightly differ between the years. ${ }^{6}$

More formally, we measure the change in the density as

$$
\hat{b}(z)=\frac{\sum_{i=z_{L}}^{z_{H}}\left[\left(c_{j}^{B} / N^{B}\right)-\left(c_{j}^{A} / N^{A}\right)\right]}{\sum_{i=z_{L}}^{z_{H}}\left(c_{j}^{A} / N^{A}\right) / N_{j}}
$$

where $c_{j}$ is the count of individuals in an income bin $j$, and $z$ denotes the income level in bin $j$, and $N^{k}$ denotes the overall number of students in the distribution. $k=B, A$, where $B$ denotes the time period before the reform and $A$ after 2008. Thus $\sum_{i=z_{L}}^{z_{H}}\left(c_{j}^{k} / N^{k}\right)$ is the relative share of students in an income bin $j$ within a fixed income range $\left[z_{L}, z_{H}\right]$. $N_{j}$ denotes the number of bins within $\left[z_{L}, z_{H}\right]$. In the estimation, we set the lower limit $z_{L}$ to zero and measure changes in the distribution below the old income threshold by setting $z_{H}$ equal to the old income threshold (9260 euros). 7

Furthermore, to estimate the causal impact of the reform on changes in the earnings distribution, we utilize a control group in the spirit of DiD. In general, factors other than the change in the location of the local discontinuity could inflict changes in labor supply behavior and the shape of the earnings distribution of students, such as overall changes in the economic environment and the local labor markets. We assume that changes in the earnings distribution of the control group reflect the potential changes in the economic environment similarly to the treatment group in the absence of the reform. Similarly to the standard DiD estimator, our estimator does not require that the two groups have income distributions that feature exactly the same shape or statistical properties. Instead, the identification assumption is that the two distributions should develop similarly over

\footnotetext{
${ }^{6}$ In the standard bunching method, using relative distributions instead of frequency distributions produces identical estimates of the relative excess bunching at a discontinuity, because in that method too the outcome of interest is measured in relative terms.

${ }^{7}$ Our estimation approach is similar in nature to other methods used to analyze changes in distributions (see e.g. Athey and Imbens 2006 and Firpo et al. 2009). However, by extending the methods used in the bunching approach, we can more feasibly relate our estimates to those derived using the bunching method that has been predominantly used to analyze behavioral responses to income notches (see Kleven 2016).
} 
time in the absence of any changes in incentives.

In our empirical application we use young part-time workers who are not higher education students as the control group. The non-student workers included in the analysis are not eligible for the study subsidy and thus not subject to the income threshold nor the reform, but are of the same age as the students and work essentially in the same local labor markets. Thus, the control group resembles the treated students as they have similar average labor earnings as students and many of these workers have more than one employer within a year. The characteristics of young, part-time workers are described in Table 28

Importantly, because individuals in both groups work in the same labor markets, we assume that any shocks affecting the labor markets would affect the earnings in both groups similarly. If this assumption holds, the distributions of both groups would change similarly over time in the absence of the reform, which is required for causal inference. We evaluate this assumption by analyzing the development of the distributions before and after the 2008 reform.

In the estimation, we follow the method described above to calculate the change in the density between the two time periods, and subtract the change in the non-student part-time workers' earnings distribution from the change in the students' distribution

$$
\hat{b_{d}}(z)=\left[\frac{\sum_{i=z_{L}}^{z_{H}}\left[\left(c_{j}^{B} / N^{B}\right)-\left(c_{j}^{A} / N^{A}\right)\right]}{\sum_{i=z_{L}}^{z_{H}}\left(c_{j}^{A} / N^{A}\right) / N_{j}}\right]^{S}-\left[\frac{\sum_{i=z_{L}}^{z_{H}}\left[\left(c_{j}^{B} / N^{B}\right)-\left(c_{j}^{A} / N^{A}\right)\right]}{\sum_{i=z_{L}}^{z_{H}}\left(c_{j}^{A} / N^{A}\right) / N_{j}}\right]^{P}
$$

where superscript $S$ denotes students and $P$ non-student part-time workers. This estimate thus summarizes the broader change in the earnings distribution of students caused by the reform while taking into account any other potential changes in the labor market environment of part-time workers 9

\footnotetext{
${ }^{8}$ The group of non-student part-time workers is selected to roughly match students' job and age characteristics. Students typically work in part-time jobs or full-time jobs for part of the year, i.e. they work less than 12 months a year. In addition, students tend to be young. Thus the control group comprises individuals who we observe to have less than 12 working months per year, and who are 19-24 years old. The age interval is chosen to match between the $25-75$ percentile points of the students' age distribution. Our results are not sensitive to small changes in the composition of the non-student group.

${ }^{9}$ Following the bunching literature, the standard errors for $\hat{b_{d}}(z)$ are calculated using a residual-based
} 


\section{Main results}

We begin by presenting the earnings distributions of students and the control group over time around the reform in 2008. Figure 3 shows the labor earnings distributions of students comprising the treatment group and non-student part-time workers comprising the control group. The figure shows the distribution for those with positive earnings within an income range of 0-18,000 euros in 2006-2007 and 2008-2009, denoting the preand post-reform years, respectively ${ }^{10}$

Remarkably, the figure shows that the earnings distribution of students has a clearly different shape in 2008-2009 than before the reform; the earnings of students have increased over a wide income range. Especially intriguing is that the increase also occurs far below the old location of the income threshold where the income distribution shifted to the right. Contrary to students, the earnings distribution of the control group remained practically constant between 2006-2007 and 2008-2009. The earnings in the control group originate from the same local labor markets as those of students in the treatment group. This suggests that the shift of the earnings distribution cannot be explained by other contemporary changes in the local labor markets affecting the earnings of both the control and treatment groups.

To quantify the changes in the distribution due to the reform, we estimate the DiD equation (2) that produces as its outcome the change in the relative density of students subtracted by the change in the density of the control group. The estimation is performed within an income range of 0-9260 euros, thus including the whole distribution below the old income threshold. The estimate is large (9.809 with a standard error of 1.01), suggesting that the magnitude of the change in the overall earnings distribution is economically and statistically significant. This estimate is approximately three times larger than the standard bunching estimate, 2.931 (0.875), estimated following the methods of Kleven

bootstrap procedure (see Kleven and Waseem 2013). First, we fit a flexible polynomial function to both the pre- and post-reform relative earnings distributions of students and other young part-time workers. We then generate a large number of new estimates for the distributions by randomly re-sampling the residuals from these regressions (with replacement). The standard error is defined as the standard deviation of $\hat{b}_{d}(z)$ based on the bootstrapped distributions.

${ }^{10}$ The figure includes only labor earnings and not all income to which the income threshold applies because receiving capital income is very rare among the students and other part-time workers. 
and Waseem (2013) within an income range just below the threshold (8100-9260 euros) before the reform $[11$ In order to further characterize the general magnitude of the response, we estimate that earnings increased on average by 550 euros when accounting for the overall changes in the shape of the earnings distribution, which corresponds to a roughly $10 \%$ average increase in labor earnings of students.

In order to be certain that the above estimates represent causal responses to the reform, we need to assume that the distributions of the treatment and control groups exhibit similar changes over time in the absence of the reform. As a first check to this end, Figure 4 plots students' and other young part-time workers' earnings distributions over a longer time period before and after 2008. The figure shows that the change in the earnings distribution of students occurred exactly at the time of the relocation of the income threshold, indicating that any gradual shifting of the distribution does not explain the observed pattern. Furthermore, the distribution of the control group also remained practically unchanged before and after 2008, therefore validating our empirical setup. In more detail, there are similar minor changes at the bottom of the distributions of both the treatment and control groups from 2004-2005 to 2006-2007, which further strengthens the case that the distributions develop similarly over time in the absence of the reform.

Our second robustness check concerns the characteristics of students in cross-sectional distributions in different years. Figure A1 in Appendix A shows the distributions in 2006-2007 and 2008-2009 when we re-weight the student population in the latter period to match the pre-reform characteristics of students in terms of age, field of study and industry. This bin-level inverse probability weighting procedure accounts for potential changes in key student characteristics over time. However, re-weighting does not change the outcomes in a significant manner, indicating that potential changes in the characteristics of the student population are not likely to explain the results.

Furthermore, one might be concerned that students can also respond by changing the number of study subsidy months they choose. First, Figure A2 in Appendix A shows

\footnotetext{
${ }^{11}$ Bunching results are discussed in more detail in Appendix B.
} 
the distributions in 2006-2007 and 2008-2009 when including students with other than the default 9 study subsidy months. The figure illustrates that the broader changes in the distribution are clearly visible when including this wider group of students, implying that labor supply responses rather than the choice of study subsidy months are driving our main results. Second, we find no significant changes in the distribution of subsidy months over time or associated with the reform, and 9 months is the most typical choice in all of the years around the reform, as illustrated in Figure A3 in Appendix A. This indicates that current students responded to the reform by changing their earnings, but not, on average, by claiming more or less subsidies per year.

In addition, an examination of students' earnings distribution in Figure 3 implies that at least a fraction of students are aware of the exact location of the income thresholds and are able to adjust their labor earnings in response to them, as bunching just below the thresholds both before and after 2008 is significant and clearly visible. Furthermore, the bunching response disappeared below the old threshold immediately after the reform. Furthermore, even though the study subsidy schedule ultimately consists of multiple notches, we observe a clear local response only to the first income threshold ${ }^{12}$

Next, we present more detailed panel data evidence of the nature of the earnings responses of students by estimating how individuals starting from different parts of the base-year income distribution change their income on average. These results highlight that many students responded to the relocation of the income threshold with a large increase in their earnings. First, in graph (a) of Figure 5 we analyze average individuallevel earnings responses when starting from different income levels in the baseline year, in 2005-2006, 2006-2007 and 2007-2008. Overall, the figure shows that average changes in individual income are very similar in the years before the reform, and that there is a visible pattern of mean reversion (on average, starting from a low income level leads to larger income in the next year, and vice versa). The figure shows that labor income

\footnotetext{
${ }^{12}$ Additional examination of excess bunching before and after the reform reveals, as further illustrated in Figure B2 in Appendix B, that relative bunching is slightly larger before the reform than after it. One intuitive explanation for this finding is that the local incentives not to exceed the notch are somewhat smaller after 2008, since the relative significance of losing one month's subsidy in terms of disposable income is now smaller than before 2008 when the threshold was at a lower income level (see Table A1 in Appendix A).
} 
increased significantly in 2007-2008 compared to the years before the reform for students originally below the threshold. This pattern is observable even for students with base-year earnings around 3000-6000 euros, which is well below the old threshold. However, we find no significant difference between the years for income bins above the new threshold, suggesting that the rapid increase in earnings below the old threshold stems from the change in the location of the income threshold.

Second, graph (b) of Figure 5 presents the likelihood of increasing individual earnings by $50 \%$ or more relative to base-year income. We observe that large increases in earnings are significantly more likely when the threshold was increased compared to previous years. The prevalence of annual earnings increases larger than 50\% doubled from 5\% to $10 \%$ in the income bins below the old income threshold at the time of the reform but remained constant between the years before 2008. In contrast, there are no significant differences in large earnings increases between the pre- and post-reform years in the bins above the new income threshold.

Third, graph (c) of Figure 5 shows that the likelihood of locating above the old income threshold in the next year increased significantly at the time of the reform, compared to the years prior to 2008. The fact that the likelihood of being located above the old notch increased even in the income bins far below the old threshold illustrates that a notable share of students responded to the reform with a large increase in their earnings when the budget constraint was relaxed at a higher earnings level. ${ }^{13}$

In summary, we find clear evidence that the 2008 reform shifting the income threshold for students induced clear earnings responses for students throughout their earnings distribution, and especially for those who were previously located well below the old income threshold. This indicates that the relaxed budget constraint induced large jumps in earnings for many students who were not directly targeted by the change based on their pre-reform earnings. We explore the potential mechanisms explaining this result in the

\footnotetext{
${ }^{13}$ Furthermore, this panel data analysis shows that the observed changes in the cross sectional earnings distributions of students discussed above stem from intensive-margin responses of students. To further support this, we find that the share of students not working at all (earning less than 500 euros per year) did not change significantly at the time of the reform. Therefore, potential extensive margin responses do not explain the change in the shape of the observed earnings distributions.
} 
next section.

\section{Conceptual framework and implied mechanisms}

The aim of this section is to discuss which labor supply models are or are not compatible with our empirical results presented above. The main feature we want to explain is the shifting of the income distribution from a wide income range below the old threshold following the change in the location of the income notch. We illustrate that a labor supply model including a discrete component can explain these results while the standard continuous models cannot. We also present the different elasticity concepts associated with different modeling choices which we then use to estimate the earnings elasticity for students, and discuss the welfare implications of discrete labor supply. In addition, we utilize this conceptual framework in our simulation model, which we use to illustrate and discuss the broader implications of discrete labor supply when estimating earnings elasticities in Section 5 ,

Our starting point is that most of the existing literature on labor supply and earnings responses to taxes, particularly the empirical literature studying the elasticity of taxable income (ETI), assumes a standard continuous choice model either explicitly or implicitly (Feldstein, 1999; Saez et al., 2012; Kreiner et al., 2015). Therefore, the continuous model constitutes a canonical framework used to analyze and measure labor supply responses to taxes and the earnings elasticity with respect to tax incentives. A popular extension to this canonical framework is to augment the continuous model with various optimization frictions that attenuate responses to tax incentives (Chetty et al., 2011; Chetty, 2012; Chetty et al., 2013; Chetty and Saez, 2013; Kleven and Waseem, 2013). The motivations for these adjustment frictions considered in the literature include job switching costs, salience of tax rules or unawareness of tax incentives, all leading to either smaller or delayed responses to tax changes.

A more fundamental deviation from the standard framework is the question of whether individual labor supply choices are discrete rather than continuous. The idea of discrete 
and inflexible labor markets is not new in the economics literature, as they have been previously analyzed and discussed in, for example, theoretical and structural labor supply literatures. For example, Lundberg and Dickens (1993) continue an older debate in economics as to whether labor supply is continuous or discrete, and provide a theoretical framework and estimations using a finite choice set for available working hours. Saez (1999) argues in one of his extensions to the standard model that workers with specific education, training and occupational skills rarely face a large set of available jobs that match their skills and preferences, thus limiting their potential to flexibly adjust their labor supply and earnings to changes in tax rates by changing their job. Kreiner et al. (2015) build and estimate a structural search model with discrete choices, motivated with similar arguments as Saez (1999). Other structural labor supply models often assume that labor supply choices (working hours) are discrete in nature, stemming from the observation that working hours often tend to cluster at certain focal points in the distribution (see van Soest 1995 and Beffy et al. 2018, and Löffler et al. 2018 for a recent review). Manning (2003) discusses the role of the labor market power of employers in limiting the labor supply responses and working hours choices of employees. Finally, Blundell et al. (2008) estimate the intensive margin labor supply responses of single mothers to changes in various in-work benefit programs in the UK. They find that the responses are governed by discrete working hours responses between jobs rather than continuous labor supply or wage rate adjustments.

Furthermore, various institutional features provide practical reasons for why annual labor supply and earnings choices could be discrete at the individual level, and that these discrete components can be rather persistent compared to more temporary adjustment frictions such as unawareness of tax incentives or job switching costs. Wage earnings can be decomposed into hourly or monthly wages and the time spent working. Both of these elements, wage rates and working time, typically include discrete or discontinuous components. First, in many types of labor markets, wage rates and working hours are regulated either by legislation or by collective agreements. These include, for example, minimum wage and minimum weekly working hours regulations. Second, discreteness 
arises from employment contracts between workers and firms. Such contracts are often mandated in labor legislation, but even in the absence of that both employees and employers can benefit from forming a contract. For a worker, fixed-term contracts ensure a predictable level of future earnings, and for the employer they guarantee a sufficient labor force for a given time period. These employment contracts typically set either the wage rate or working hours or both for a fixed period of time and also include a fixed notice period, inducing discreteness in the available labor supply and earnings choices of an individual.

\subsection{Labor supply models}

Next, we present and discuss the different labor supply models in more detail. We start with a canonical continuous model and then extend that with adjustment frictions and discrete choice sets. A continuous-choice framework features a utility function over consumption and leisure and a linearized budget set consisting of earnings, consumption and income taxes. The utility function is $u(c, z)$, where $c$ denotes consumption (net earnings) and $z$ gross earnings, and $u_{c}>0$ and $u_{z}<0$. We abstract from income effects following the earlier literature, and including them would not change the main results in qualitative terms but would complicate the formulas. The budget set is described as $c=(1-\tau) z+R$, where $(1-\tau)$ is the net-of-tax rate and $R$ is virtual income.

In our analysis, we follow the earlier literature and for simplicity parameterize the utility function to a quasi-linear form as follows:

$$
u(c, z)=c-\frac{w^{i}}{1+\frac{1}{e}}\left(\frac{z}{w^{i}}\right)^{1+\frac{1}{e}}
$$

where $w^{i}$ is an ability (productivity) parameter of individual $i$ over which individuals are heterogeneous. Thus, the utility maximization with respect to $z$ gives the optimal choice for an individual, $z^{*}=w^{i}(1-\tau)^{e}$, where $e$ is the earnings elasticity parameter with respect to $\tau$, capturing the earnings responses to taxes. Thus the earnings choices are determined in this parameterized model by the response to marginal tax rates given 
the innate productivity $w^{i}$ and $e$ parameter. More generally, earnings elasticity in the continuous-choice model can be expressed as

$$
e=\frac{d z}{d(1-\tau)} \frac{1-\tau}{z}
$$

Next, suppose that there is an increase in the tax rate above a certain income threshold. In the continuous model, if we start from an individual's optimal income choice $z^{*}$ and do not change the tax system applied to this location, individuals will not respond by changing their labor supply. Therefore, if tax rates are changed at a higher earnings level, this model cannot capture any responses occurring to individuals below the point of the (marginal) tax rate change. Hence, the continuous model cannot capture or explain earnings responses from below the income threshold in our empirical case. Finally, panel (a) of Figure A4 in Appendix A illustrates the indifference curves and budget sets when there is an increase in the location of an income notch in the continuous model.

Adjustment frictions or adjustment costs can be included in the parameterized continuous model by adding to the utility function a friction parameter $a \in(0,1)$. If $a$ is close to one, responses to taxes would be minimal, and if $a$ is close to zero, responses to taxes would occur according to the standard model. The utility function then becomes as follows

$$
u(c, z)=c-\frac{w^{i}}{1+\frac{1}{e(1-a)}}\left(\frac{z}{w^{i}}\right)^{1+\frac{1}{e(1-a)}}
$$

From the above equation it becomes clear that considering these types of optimization frictions merely reduces the responsiveness to taxes, but they do not alter individual responses to taxes in a more fundamental manner. Therefore, this model does not produce earnings responses from below the earnings level where the tax rate is changed 14

We can further alter the canonical framework by adding optimization errors to the model, arising from an unanticipated shock to the initially chosen income. A simple

\footnotetext{
${ }^{14}$ Heterogeneous adjustment costs do not change this intuition, but could explain why some taxpayers respond to taxes while others do not.
} 
approach to including optimization errors is to consider an error parameter drawn from some distribution, $r \in f(r)$. First, a taxpayer makes an optimal earnings choice $z^{*}$, and then the optimization error alters this choice by $r$, such that the final outcome is $z^{*}-r$. A crucial aspect of optimization errors is that they are unanticipated and thus do not enter the model when the optimal earnings choice is made. 15 Therefore, these kinds of frictions would typically cause only small deviations in income and lead to, for example, some individuals being located in the dominated range above an income notch. However, optimization errors do not, by definition, induce large responses to changes in tax incentives, and therefore cannot explain income responses over a broad income range below a notch.

Following Saez (2002), we model discrete labor supply through a constraint stating that an individual chooses her earnings level from a set of discrete earnings locations. Thus the choices are discrete even conditional on participating in the labor market. More formally, individuals choose from a discrete set of alternative earnings location choices $j=$ $1, \ldots, N$, yielding utility $u\left(c_{j-1}, z_{j-1}\right), u\left(c_{j}, z_{j}\right), u\left(c_{j+1}, z_{j+1}\right)$, but individual preferences and the underlying ability distribution are similar as before. Thus, the utility function is the same as above but indexes the discrete choices with $j$, denoting the available earnings choices for an individual. The budget set is now described as $c_{j}=w_{j}-T_{j}+R$, where $T_{j}$ is the average tax at location $j$. The discrete choice the individual chooses is determined by which location yields the highest utility:

$$
u\left(c_{j-1}, z_{j-1}\right) \leq u\left(c_{j}, z_{j}\right)=c_{j}-\frac{w^{i}}{1+\frac{1}{e}}\left(\frac{z_{j}}{w^{i}}\right)^{1+\frac{1}{e}}
$$

The main conceptual difference between this model and the continuous model is that individuals now consider their utility in all potential states, $z_{j-1}, z_{j}, z_{j+1}$. Intuitively, if the tax rate changes at either $z_{j-1}$ or $z_{j}$, this can affect the location choices of an individual even when the change in the tax rate occurs further away from the current location in the earnings distribution. Therefore, a model including a discrete choice

\footnotetext{
${ }^{15}$ If individuals have an expectation of the shock or are risk-averse, they could respond to the expectation but not to the realized shock.
} 
component can rationalize much larger jumps in earnings as a response to a local tax rate change compared to any of the continuous models considered above. Consequently, it also rationalizes earnings responses over a wide income range below the notch in our empirical example. Figure A4 in Appendix A further illustrates the intuition of how the discrete model can lead to a large jump from far below the original location of the notch when the location of a notch is increased, whereas the continuous model cannot.

Finally, when labor supply choices are discrete, the elasticity concept derived from the canonical continuous-choice model is not the correct one. Instead, the correct concept is mobility elasticity (Saez, 2002; Kreiner et al., 2015). Mobility elasticity measures the earnings responses when individuals move from one discrete earnings location to another as a response to a change in the average tax rate across these distinct locations. Following Kreiner et al. (2015) and Saez (2002), we can express mobility elasticity with the following equation:

$$
\zeta=\frac{d Y}{d(1-m)} \frac{1-m}{Y}
$$

, where $m$ is the average tax rate difference between two different earnings locations $j$ and $j-1, m=\frac{T_{j}-T_{j-1}}{w_{j}-w_{j-1}}$, and $Y=\sum_{j=1}^{N}\left(z_{j} g_{j}\right)$ where $z_{j}$ is earnings and $g_{j}$ the relative mass of individuals in each earnings location.

Equation (7) thus captures the change in earnings inflicted by individuals moving between different earnings locations due to changes in the average tax rate differential between these locations. This elasticity formula captures two important features that are missing from the continuous-choice specification when considering discrete responses. First, mobility elasticity captures earnings responses over a broader income range across multiple earnings locations, denoted above by $d Y$. Second, the standard measure for the change in the marginal tax rate does not necessarily capture the actual change in tax incentives across distinct earnings locations, whereas the term $m$ in the mobility elasticity formula does. 


\subsection{Earnings elasticity estimates and welfare implications}

We apply the mobility elasticity formula presented above in equation (7) to approximate the earnings elasticity of students. We utilize the relocation of the income threshold and examine changes this caused in the income distribution. To obtain an empirical estimate, we simplify the model by assuming that students choose from two earnings locations: one below the old income threshold and one above it. First, we define the average earnings locations of students below and above the old income threshold in order to calculate the change in net incomes between these locations due to the reform. This constitutes a theoretically meaningful measure for the change in tax incentives in the discrete choice model. Average gross earnings were 6008 euros below the old threshold in 2007 in the income range of 2000-9200 euros, and 11,821 euros above the old threshold in 2008 in the income range of 9201-18,000 euros. ${ }^{16}$ Then we use the tax and subsidy rules before and after the 2008 reform to derive the net incomes at these locations. Due to the shifting of the notch, the net earnings difference between these two locations increased mechanically from 3534 to 4807 euros.

Next we define the change in earnings caused by individuals moving between the earnings locations in the discrete model. Average earnings were 7116 euros and 7529 euros in 2007 and 2008, and thus the average real earnings within an income range range of 2000-18,000 euros increased by 413 euros from 2017 to 2018.17 To calculate the mobility elasticity, we relate the average change in log gross earnings to the log change in the difference in net incomes between the average earnings locations below and above the threshold. This delivers a mobility elasticity estimate of 0.183 .18 Therefore, even though the reform caused large and distinctive earnings responses over a wide income range, the strong incentive change caused by the reform implies that the earnings elasticity estimate is nevertheless modest. Our estimate is also close to earlier earnings elasticity estimates in the literature (see Saez et al. (2012) for a survey) and also close to what Søgaard (2019)

\footnotetext{
${ }^{16}$ We limit our analysis to the income range of $2000-18,000$ euros as there were no changes in the distribution in the area below 2000 or above 18,000 euros between 2007-2008 (see Figure 3).

${ }^{17}$ As illustrated in Figure 4 , there were no significant changes in the annual earnings of students in years absent the 2008 reform.

${ }^{18}$ Table A2 in Appendix A presents the variables used to calculate the mobility elasticity estimate.
} 
finds for university students in Denmark who face a similar income threshold involving a kink instead of a notch.

How does our simplified characterization of the mobility elasticity compare to an estimate derived using a continuous choice framework? Using the reduced-form earnings elasticity formula for income notches presented in Kleven and Waseem (2013), we obtain a local elasticity estimate of $0.065(0.007)$ for students with 9 subsidy months when utilizing bunching responses to the income threshold (see Appendix B for more details on the estimation procedure). Therefore, in this case, the continuous-choice model delivers an earnings elasticity estimate that is approximately 2.5 times smaller than in the discrete choice framework. ${ }^{19}$ This difference stems from the fact that the bunching method underestimates the extent of the overall behavioral response to the notch. As the relocation choices of students occurred from far below the old threshold, the bunching responses estimated using the stationary distribution just below the notch have a limited potential to capture all relevant earnings responses to the income threshold.

More broadly, discrete labor supply could provide an explanation for why we tend not to observe bunching at tax rate kinks but do tend to find significant earnings elasticity estimates from the same countries and contexts when using methods that capture earnings responses from a wider income range. For example, in the US, bunching responses at income tax rate kinks for other individuals than the self-employed are very small or zero (Saez 2010), but the DiD estimates for ETI are typically significantly larger even for regular wage earners (see Saez et al. 2012 and Weber 2011). Similar evidence is also available for Sweden (see Bastani and Selin 2014 and Blomquist and Selin 2010) and Denmark (see Kleven and Schultz 2014 and Chetty et al. 2011). We discuss the more general implications of discrete vs. continuous models for earnings elasticity estimates in Section 5

\footnotetext{
${ }^{19} \mathrm{An}$ alternative approach to measure the difference between the approaches is to relate the broader changes in the distribution to the local estimate derived from the continuous model. In Figure 3 , we find that the broader relative changes in the earnings distribution are approximately three times larger than the bunching estimate just below the threshold (9.81 vs. 2.93). Overall, these findings imply that when earnings choices are discrete, the bunching method can significantly underestimate the true earnings responses.

${ }^{20}$ Even though the bunching method has clear limitations when earnings choices are discrete, it can be a useful method in other contexts. For example, bunching estimates can deliver relevant evidence of
} 
Furthermore, earnings elasticity estimates are tightly linked to welfare analysis of income taxes and income transfers. A key method for analyzing the welfare losses of income taxes and transfers is the sufficient statistic approach (see e.g. Chetty 2009a), where the idea is to estimate a single reduced-form parameter to measure the welfare loss. Following Chetty (2009b) and Slemrod (1998), the welfare ( $W$ ) effect of a tax rate change can be formalized as follows

$$
\frac{d W}{d \tau}=\frac{d R}{d \tau}-\left.\frac{\partial R}{\partial \tau}\right|_{M}
$$

where $d R / d \tau$ denotes how total tax revenue (aggregate earnings over all individuals times the tax rate) responds to a change in the tax rate, and $\partial R /\left.\partial \tau\right|_{M}$ denotes the mechanical change in revenue absent any behavioral responses. The welfare loss stems from the extent to which (taxable) earnings respond to a change in the tax rate. As discussed in Chetty (2009a), the underlying earnings response mechanism does not change the basic idea of the sufficient statistic approach. For example, assuming discrete rather than continuous labor supply choices does not change the sufficient statistic formula. However, as discussed above, the correct elasticity concept can depend on the chosen model, and that affects the estimation method and could significantly impact the size of the estimated elasticity used to measure the welfare loss.

The fundamental aim of the welfare analysis is to estimate a structural long-run elasticity unaffected by any short-run frictions (Chetty, 2012; Kleven and Waseem, 2013). The estimated earnings elasticity under temporary adjustment frictions, such as inattention to taxes or optimization errors, tends to be lower than the structural long-run elasticity (Chetty, 2012). In contrast, discrete labor supply is not a temporary friction, but rather discreteness is a permanent constraint for labor supply. Therefore, the observed elasticity in a pure discrete labor supply model is also the structural elasticity. Thus, different optimization frictions have very different welfare implications. Also, the observed elasticities constrained only by discreteness in labor supply are the sufficient

behavioral responses among business owners and the self-employed or when detecting tax avoidance and evasion responses. In these instances, discrete choices are not a likely constraint for earnings responses. 
statistics for welfare losses. Empirically observed behavior is likely to be constrained by both adjustment costs and discreteness, and thus both arguments may hold at the same time.

Finally, as argued in Chetty (2012), earnings responses to very distinctive changes in incentives can produce an elasticity estimate that is less affected by any short-run frictions, such as inattention. However, under discrete labor supply the argument changes, and then what matters more is whether a large fraction of individuals can meaningfully change earnings location as a response to a tax change, and the short- vs long-run is not as essential argument. Relatedly, Kleven and Waseem (2013) argue that utilizing the share of individuals located in the region of dominated choice just above an income notch can deliver relevant information on the extent of short-run frictions affecting the earnings adjustments to taxes. However, the dominated range is not necessarily a suboptimal choice for an individual who faces a discrete choice constraint, as an available earnings location might be optimal even when it is directly above a notch, if other choices are sufficiently far away from it. Therefore, when labor supply is discrete, following the approach in Kleven and Waseem (2013) and relating the share of individuals in the dominated range to the estimated local counterfactual does not deliver a consistent measure of to what extent optimization frictions affect responses to taxes.

\subsection{Further empirical evidence of discrete earnings responses}

Above we provided theoretical reasoning for how discrete choice elements explain our empirical results. Next, we provide further empirical evidence of the role of discrete labor supply. We examine the responses of two specific subgroups of students working in labor markets featuring more or less discreteness: those who work in the public sector, or research, manufacturing and construction in the private sector, and those working in restaurants, bars and cafes, hotels and other accommodation services, cleaning and security services, and retail sales such as supermarkets and gas stations. The latter group typically have more flexible working hours and are more likely to be subject to hourly rather than monthly wages, compared to the first group. Therefore, students in 
the latter group are more likely to have less discrete labor supply compared to the first group.

Figure 6 shows that the changes in the earnings distribution over a broader income range after the 2008 reform are smaller for those students who work in less discrete labor markets $(6.14(1.71))$, and larger for those working in jobs with less available discrete choices $(10.94(1.10))$. This difference in the amount of shifting in the distributions supports our hypothesis that discrete responses are a key factor explaining the main result of widespread income responses from far below the notch. However, we also detect statistically significant responses over a wide income range for those in the first group, illustrating that discrete labor supply can induce a relevant constraint even in more flexible labor markets, consistent with our notion that discrete labor supply is a feasible framework to consider for all wage earners. Also, these findings suggest that the discreteness can differ significantly between different types of labor markets, which can lead to differences in the estimates of observed behavioral responses to tax incentives. We further discuss this in Section 5.3 .

\section{Broader empirical implications of discrete labor sup- ply}

In this section, we further analyze the labor supply mechanisms and demonstrate the welfare implications of discreteness in labor supply. First, we present the simulation model we use in this analysis. Then we provide simulation results that illustrate the mechanisms behind the income responses of students under different modeling assumptions, highlighting that a discrete model as opposed to a continuous model qualitatively matches our empirical findings. The analysis proceeds by presenting how standard reduced-form tax elasticity estimates based on a continuous model can be biased when labor supply is discrete rather than continuous. 


\subsection{Simulation model}

We build our simulation model on the theoretical framework presented in Section 4. The individual utility function is given in equation (3), where the $e$ parameter governs the disutility from earnings supply and would correspond to the elasticity with respect to taxes in the continuous model. The discrete model has the same utility function but adds a fixed number of discrete earnings choices to the individual decision problem as an additional constraint. The budget set for individuals arises from the tax system included in the simulations which we discuss below.

The model assumes an underlying ability distribution from which each individual $i$ receives a predetermined draw $w_{i}$. This draw represents earnings in the absence of responses to the tax system. Our parameterized ability distribution is presented in Figure A5 in Appendix A. ${ }^{21}$ The available discrete earnings locations for each individual are drawn from the probability distribution presented in Figure A6 in Appendix A. The number of choices drawn can be altered in different specifications and the draws vary between different individuals. Therefore, even when the individual-level choices are discrete, the overall earnings distribution is smooth. In the model, we focus on discrete labor supply conditional on participating in the labor market, and, for simplicity, exclude the labor market participation margin from the analysis.

\subsection{Discrete vs. continuous model}

First we simulate earnings distributions when the budget set includes an income notch, a scenario that resembles our empirical case for university students. In this exercise, we assume the parameters given in Table 3. The marginal income tax rate is set at $22 \%$ below the notch and a high marginal tax rate of $61 \%$ is applied above the notch, constituting a simplified linear version of the actual budget set for students including multiple notches above the income threshold (see Figure 1). The size of the notch, i.e. the size of the drop

\footnotetext{
${ }^{21}$ The distribution is a combination of power distributions and normal distributions, which gives an approximate match for the shape of the empirical earnings distribution of students in our empirical case. Our results are not sensitive to different underlying ability distributions that roughly match the empirical income distribution of students.
} 
in disposable income at the income threshold, is 500 euros. The notch is relocated from 9000 to 12,000 euros in the simulated reform.

Figure 7 shows the simulated earnings distributions within an income interval of 0-25,000 euros using the baseline continuous model and 0.2 as the value for the $e$ parameter ${ }^{22}$ The different panels in the figure present the baseline continuous model (panel a), the continuous model supplemented with adjustment frictions (panel b) and with both adjustment friction and optimization errors (panel c) ${ }^{23}$

First, we find that bunching at the income threshold is sharp and sizable both before and after the reform in panel (a). Adding adjustment frictions to the model according to equation (5) in panel (b) only leads to slightly smaller bunching and slightly more individuals being located just above the notch, but no changes in earnings over a broader income range. Adding i.i.d. earnings shocks as optimization errors in panel (c) yields more diffuse bunching, but again no earnings responses over a wider income range below the old income threshold 24

Next, we add discrete choices as an additional constraint. Figure 8 illustrates the earnings distributions using 30, 15, 10 and 5 available earnings choices for each individual and assuming an underlying $e$ parameter of 0.5 . With a discrete choice constraint included in the model, the earnings distributions and the response to the reform qualitatively resemble the empirical distributions (see Figure 3). In particular, when the number of discrete choices is set at 10 (on average, earnings jumps of 2500 euros or 10-30\% relative to the baseline income level), the qualitative shape of the distributions largely resembles their empirical counterparts. First, the earnings distribution shifts to the right from a relatively wide income range below the old threshold. Second, the shape and amount of excess bunching below the threshold are approximately of the same nature and order of

\footnotetext{
${ }^{22}$ Qualitative simulation results are not sensitive to the choice of the $e$ parameter, except that with higher parameter values the densities above the thresholds reduce.

${ }^{23} \mathrm{We}$ assume heterogeneous adjustment frictions represented by a uniformly distributed parameter $a$ in the unit interval. Each individual has a different and independent draw from this distribution. The earnings shocks related to optimization errors are normally distributed mean-zero income shocks with a standard deviation of 800 euros.

${ }^{24}$ If we were to assume only negative income shocks we would obtain diffuse bunching only below the notch, similarly as in the empirical distribution. However, such asymmetric shocks cannot be not easily justified.
} 
magnitude as in our empirical case. Note that scattered bunching below the threshold only results from including discrete earnings choices as a constraint, as this model does not include optimization errors or adjustment frictions. Furthermore, when increasing the number of available discrete locations the distributions begin to resemble those in the continuous model, and with only a very small number of available choices both the broader changes in the distribution and the bunching responses are small, as can be expected.

Overall, these findings further support the conclusion in Section 4.1 that the canonical continuous-choice model cannot explain our empirical findings, not even when complemented with adjustment frictions or optimization errors. In contrast, we need a discrete choice component in the model in order to be able to at least qualitatively explain the earnings responses from far below the old income threshold. Nevertheless, other elements such as optimization errors and inattention could also play a role in the observed responses of students, which might be needed in order to more precisely model the labor supply behavior. However, the main point of this simulation exercise is to highlight that a discrete component is required in order to even qualitatively model the discrete jumps in earnings from below the threshold.

\subsection{Tax elasticity estimation}

In this section, we illustrate the impact of the labor supply model on elasticity estimation and the potential biases therein based on the theoretical considerations presented in Section 4.1. We highlight the implications of the labor supply adjustment process for the elasticity estimates, and focus on the case where the continuous model is assumed but actually labor supply is discrete. Moreover, we illustrate and discuss how mobility elasticity estimates vary depending on the details of the tax reform and the number of available discrete choices.

First, we discuss how the continuous versus discrete model would affect the reducedform methods for estimating the earnings elasticity. Typically, estimates for the ETI are conducted using a DiD approach utilizing a treatment group facing a tax reform and 
a control group assumed to be unaffected or differentially affected by the reform (see e.g. Saez et al. (2012) for more details of the typical estimation procedure). Therefore, a crucial part of the estimation is how the treatment and control groups are defined. Usually, the treatment group is selected to include only those individuals who face a tax rate change based on their pre-reform earnings. Moreover, typically the control group is individuals with slightly different (usually lower) pre-reform earnings, because it is not possible to find a group of individuals with the exact same pre-reform earnings levels as the treatment group, but who did not face a change in taxes. This is the case, for example, in the seminal paper by Gruber and Saez (2002) and many subsequent studies.

In general, when the actual labor supply model is continuous, the above definitions for the treatment and control groups can deliver an unbiased earnings elasticity estimate. However, when labor supply is discrete instead of continuous, these definitions are not necessarily consistent. In the discrete model, individuals outside the earnings region where the tax reform occurs can respond to the reform, as discussed in Section 4.1. This raises two main issues in the standard estimation. First, a typically defined treatment group excludes those who could respond to the tax reform but were not located in the earnings region where the tax rate change occurred before the reform, thus excluding part of the actual earnings responses to the reform. Second, a typically defined control group could include individuals who are in fact affected by the tax reform in a similar manner as the treatment group, thus introducing another bias in the estimate.

Next, we illustrate the bias numerically using our simulation model and a simulated tax reform. The benefit of using the simulation approach is that we can precisely observe all the income responses in the simulated data, enabling us to track down the impact of discrete responses and other sources of the bias on the elasticity estimate.

In the simulation, we utilize an underlying income distribution calibrated to match the empirical distribution of the students (income range of 0-25,000 euros with mean income of approximately 6000 euros). We simulate an institutional setting including a kinked tax schedule where the marginal tax rate increases above a given income level. In our baseline case, the tax schedule features a marginal income tax rate of $40 \%$ which jumps to $60 \%$ for 
earnings of 10,000 euros onward. We then introduce a reform that repeals this kink and reduces the tax rate to $40 \%$ also from the 10,000 euro threshold onward. Therefore, this set-up and the simulated reform would correspond to a large marginal tax rate cut for higher incomes, in a similar vein as the widely studied Tax Reform Act of 1986 in the US (Feldstein, 1999; Saez et al., 2012). In the baseline model, we assume an e parameter of 0.5 and 10 available discrete earnings choices for each individual, parameter values that yield baseline simulation that qualitatively matches the observed earnings responses of students to the study subsidy threshold reform. We later vary these parameters to show the sensitivity of the results to them. Again, we focus on discrete labor supply choices conditional on participating in the labor market and exclude the participation margin from the model, which enables us to better compare the estimates to those derived in the ETI literature that focuses on intensive margin earnings responses.

Formally, the standard ETI estimation is usually performed by regressing the change in log income on the change in the log of the net-of-tax rate as follows

$$
d \log z_{i t}=\varepsilon d \log (1-\tau)_{i t}+\epsilon_{i t}
$$

where subscript $i$ refers to the individual and $t$ time, $z$ (taxable) earnings, $\tau$ marginal tax rate, $\epsilon$ the error term, and $\varepsilon$ is the estimated average earnings elasticity with respect to the net-of-tax rate.

The empirical mobility elasticity formula we use in the analysis differs from this specification in two important ways. First, we account for the fact that when earnings choices are discrete, individuals below the original kink point can also be affected by the reform. We denote the tax rate $(m)$ as the difference between net earnings relative to gross earnings in different locations, as discussed in Section 4 . Empirically, $m$ can be calculated by estimating the average change in income due to the reform by income bin and denoting the initial earnings location as $i-1$ and the new location (pre-reform income plus the average change in income) as $i$. This implies that the change in the tax rate is potentially non-zero for a large part of the earnings distribution also below the original kink. Formally, the mobility elasticity is estimated with the following equation 


$$
d \log z_{i t}=\zeta d \log (1-m)_{i t}+\epsilon_{i t}
$$

where $\zeta$ denotes the average mobility elasticity.

Figure 9 illustrates the simulated earnings distributions in the discrete case before and after the reform, and for a comparison, Figure 10 presents the distributions assuming continuous choices. These figures show that there is a significant and sharp bunching in the continuous case but no clear bunching in the discrete case prior to the repeal of the tax rate kink. Furthermore, the shape of the earnings distribution changes over a broader region below the kink point in the discrete case but no such changes occur in the continuous case, similarly as in our empirical results for students.

To more clearly describe how individuals respond to the reform, Figure 11 presents the individual-level earnings responses and incurred tax rate changes within the reform for both the discrete and continuous cases. In the figure, the responses are denoted in terms of pre-reform earnings using 200 euro income bins (horizontal axis). According to the assumptions described above, in the continuous case the change in log earnings and the change in the net-of-tax rate are zero for those originally below the kink. The change in log earnings is a constant 0.2 above the kink point (except for a narrow local bunching window just around the original kink point) and the change in the log of the net-of-tax rate is 0.4 above the kink. 25

These patterns are different in the discrete case. First, the change in the tax rate $m$ does not always coincide with the change in the marginal tax rate used in the continuous model. The tax rate changes do coincide above the original kink because in the linear tax system the change in taxes caused by jumping between two distinct earnings locations equals the change stemming from a marginal earnings adjustment. However, unlike in the continuous case, some individuals below the original kink also face a change in their tax rate if their next available earnings location is above the kink point. Furthermore,

\footnotetext{
${ }^{25}$ The intuition for the continuous model remains similar if we include adjustment frictions in the model as in Section 4.1. Under constant adjustment frictions, the behavioral responses would be smaller above the kink, but there would be no behavioral responses for individuals below the original kink point. Adding heterogeneous adjustment frictions across individuals would produce variation in the size of the behavioral responses above the kink, but again no responses for individuals originally below it.
} 
the average change in the tax rate reduces the further we move below the original kink, as the share of individuals with their next available earnings location above the kink point reduces. Second, due to the changes in incentives also for individuals below the original kink, the average change in log earnings is not zero in this earnings region in the discrete case, as already discussed above.

Next, we estimate the earnings elasticities by plugging the simulated data representing the earnings responses and tax incentive changes into equations $(9)$ and $(10)$. Figure 12 illustrates the average tax elasticities by pre-reform earnings using 200 euro bins. As can be expected, the standard continuous model produces a constant elasticity estimate of 0.5 above the kink point, which equals the chosen $e$ parameter in the simulation model. In contrast, the mobility elasticity estimate in the discrete model is smaller and not constant across the distribution. On average, the mobility elasticity is 0.14 , and 0.2 above the original kink and 0.12 below it.

As explained above, quasi-experimental ETI estimates could be biased when assuming the continuous model but when the actual earnings responses are discrete. Figure 12 illustrates this by showing how the estimated elasticity would change when treating those directly below the kink point as a control group. Then, we would effectively subtract their earnings elasticity from that of the treatment group that was originally located above the kink point. As also those who were below the location of the kink can respond to the reform when the choices are discrete, this method could induce a significant downward bias in the elasticity estimate, illustrated in Figure 12 . Note that if the actual responses were continuous, there would be no such bias in the estimate because in that case the earnings responses and the earnings elasticity below the kink are zero.

Next, we characterize the extent of this bias in the "naive" DiD estimate utilizing simulated microdata and the estimation methods described above. In the naive estimator, define the treatment group as those individuals who were above the kink based on their pre-reform earnings, and as the control group those individuals whose pre-reform earnings were within an income range of 8000 euros below the kink to the kink. We also estimate the mobility elasticity using equation (10) where we consider as treated all those 
individuals who face a tax rate change irrespective of their pre-reform earnings, similarly as above in Figure 12 .

Table 4 collects the estimates when assuming the discrete case with 10 available earnings choices and varying the location of the original kink point. The results show that the naive ETI estimate is always smaller than the mobility elasticity estimate, demonstrating the downward bias in the estimate stemming from the earnings responses of those below the kink in the control group. A comparison between the naive ETI and mobility elasticity estimates in Table 4 suggests that the size of this bias can be notable. Using the baseline specification where the original kink is located at 10,000 euros, the mobility elasticity estimate is almost twice as large as the naive ETI estimate (0.177 vs. 0.098).

Furthermore, in Table 4 both the naive ETI and mobility elasticity estimates are consistently smaller in the discrete model than in the baseline continuous model (elasticity 0.5). As we have calibrated our discrete model to approximately match the empirical results for students, we believe that this results would represent what would happen in many actual empirical settings. Therefore, discrete earnings constraints could constitute a feasible reason for why many empirical studies find small or moderate ETI estimates (see Saez et al. 2012 and Neisser 2019), even when the estimation does not suffer from the downward bias discussed here. However, this feature is sensitive to the parameters chosen in the simulation model, and when the tax reform occurs at lower income levels and when we increase the number of available earnings choices, the elasticity estimates in the discrete framework can even exceed those estimated from the continuous model. We discuss reasons for this below.

Tables A3 A5 in Appendix A present the estimates when varying the number of available earnings choices and the location of the original kink point. First, we can observe that the higher the original kink is in the income distribution the lower is the mobility elasticity estimate. In the simulation model the available earnings locations are closer to each other at lower income levels, and thus a larger number of individuals change their earnings locations as a response to the reform, thus leading to a larger mobility elasticity estimate. Relatedly, the bias in the naive ETI estimate is smaller the 
less discrete the earnings choices are. Therefore, the degree of discreteness provides a reason for why empirically the earnings elasticity estimates are likely to be larger in cases where individuals can easily adjust their earnings, such as for business owners and top income earners, as is typically observed in the empirical literature (Saez et al., 2012; Neisser, 2019). This is because both the estimates are less downward biased and the true responses are larger.

Furthermore, in a study related to ours Kreiner et al. (2015) find that the earnings elasticity might be larger in the long run than in short run in their model with discrete job-search behavior, which resembles our discrete labor supply model. The mechanism Kreiner et al. (2015) illustrate is that with a discrete number of alternative choices individuals respond by making larger jumps in their earnings when they switch between jobs compared to a standard continuous model. Our simulations are in line with this, but also show that a significant fraction of individuals do not respond at all to changes in tax incentives because of a larger distance between the available earnings locations in the discrete model. Thus the average labor supply response could be either larger or smaller under the discrete compared to the continuous model depending on which of the mechanisms dominate. In our simulation calibrated to match the empirical data, it seems that the latter effect dominates and the average income elasticity is reduced when the available earnings choice set is sufficiently discrete.

Overall, our main finding from these simulations is that the interpretation of the DiD elasticity estimates in earlier studies can be very sensitive to the underlying labor market constraints and the labor supply mechanisms. If the actual responses are discrete they can create a significant bias when using standard methods based on the assumption of continuous labor supply to estimate the elasticity. Nevertheless, this bias is not relevant for all quasi-experimental tax elasticity estimators. For example, the literature studying the impact of the earned income tax credit (EITC) on earnings in the US typically applies an estimation strategy where women without children are used as a control group for women with children, who are eligible for larger tax credits (see Kleven (2019) for a recent review). In these types of set-ups, the control group is typically unaffected by 
the changes in taxes occurring for the treatment group, implying that potential discrete responses do not bias the estimates in this case.

\section{Concluding remarks}

In this paper, we found clear reduced-form evidence of discrete labor supply determining the responses to changes in tax incentives. We found that a reform that shifted the location of an income notch for Finnish higher education students led to widespread earnings responses over a wide income range below the notch. We argue that this finding is not consistent with a continuous labor supply model even when augmented with adjustment costs such as search frictions, but the responses are consistent with a simple discrete labor supply model. Given that university students often work in more temporary labor markets associated with short-term contracts and flexible working hours, we think that discrete labor supply is an even more relevant mechanism for labor markets in general where contracts are more often permanent and established. Thus we argue that discreteness of labor supply is a relevant component to consider in all models that analyze labor supply behavior.

Furthermore, we analyzed the implications of discrete labor supply on empirical estimation methods and the magnitude of the income elasticity with respect to income taxes. We found that standard differences-in-differences and bunching methods for estimating the elasticity need to be adjusted when the labor supply is discrete. Discrete labor supply choices expand the group of individuals who are potentially affected by tax rate changes, and consequently narrow down the group of individuals who can be used as a valid control group. We found that not taking this issue into consideration could result in a significant downward bias in the elasticity estimate. Also the relevant tax rate concept for the elasticity changes from marginal tax rate to average tax rate when choices are discrete.

Our results also have direct welfare implications, because they affect the interpretation of how large is the underlying structural elasticity which is the concept used in welfare 
measurements. If discreteness is a permanent constraint in the labor supply model, the observed empirical elasticity is also the underlying structural elasticity and thus the sufficient statistics for welfare analysis. This is unlike with other optimization frictions that could only temporarily reduce the elasticity, and thus create a wedge between observed empirical and underlying structural elasticity. We argued that the functioning of the labor markets that cause the discreteness in labor supply could be permanent features, such as the need to form contracts between employers and employees. If some of the discreteness could be changed, that could be a policy tool in itself affecting welfare, as argued by Bastani et al. (2015).

In principle, discreteness could either reduce or increase the true elasticity. In our simulation model calibrated to match our empirical data, we found that the average income elasticity is reduced compared to the continuous model when the available earnings choice set is sufficiently discrete. In a small set of simulations we found the opposite case that the elasticity increased, but we regard these as less relevant for describing the average responsiveness of the workforce to income taxes.

\section{References}

[1] Athey, S. and G. Imbens (2006). Identification and Inference in Nonlinear Differencein-differences Models. Econometrica, 74(2): 431-497.

[2] Bastani, S., Blumkin, T. and Micheletto, L. (2015). Optimal wage redistribution in the presence of adverse selection in the labor market. Journal of Public Economics, 131: 41-57.

[3] Bastani, S. and H. Selin (2014). Bunching and Non-bunching at Kink Points of the Swedish Tax Schedule. Journal of Public Economics, 109: 36-49.

[4] Beffy, M., R. Blundell, A. Bozio, G. Laroque and M. To. (2019). Labour Supply and Taxation with Restricted Choices. Journal of Econometrics, 211: 16-46. 
[5] Blomquist, S. and H. Selin (2010). Hourly Wage Rate and Taxable Labor Income Responsiveness to Changes in Marginal Tax Rates. Journal of Public Economics, 94(11-12): 878-889.

[6] Blundell, R., M. Brewer and M. Francesconi (2008). Job Changes and Hours Changes: Understanding the Path of Labor Supply Adjustment. Journal of Labor Economics, 26(3): 421-453.

[7] Chetty, R. (2009a). Sufficient Statistics for Welfare Analysis: A Bridge Between Structural and Reduced-Form Methods. Annual Review of Economics, 1: 451-488.

[8] Chetty, R. (2009b). Is the Taxable Income Elasticity Sufficient to Calculate Deadweight Loss? The Implications of Evasion and Avoidance. American Economic Journal: Economic Policy, 1(2): 31-52.

[9] Chetty, R. (2012). Bounds on Elasticities with Optimization Frictions: A Synthesis of Micro and Macro Evidence on Labor Supply. Econometrica, 80(3): 969-1018.

[10] Chetty R., A. Looney and K. Kroft (2009). Salience and Taxation: Theory and Evidence. American Economic Review, 99(4): 1145-1177.

[11] Chetty, R., J. Friedman, L. Pistaferri and T. Olsen (2011). Adjustment Costs, Firm Responses, and Micro vs. Macro Labor Supply Elasticities: Evidence from Danish Tax Records. Quarterly Journal of Economics, 126(2): 749-804.

[12] Chetty, R., J. Friedman and E. Saez (2013). Using Differences in Knowledge Across Neighborhoods to Uncover the Impacts of the EITC on Earnings. American Economic Review, 103(7): 2683-2721.

[13] Chetty, R. and E. Saez (2013). Teaching the Tax Code: Earnings Responses to an Experiment with EITC Recipients. American Economic Journal: Applied Economics, $5(1): 1-31$.

[14] Dickens, W. and S. Lundberg (1993). Hours Restrictions and Labor Supply. International Economic Review, 34 (1): 169-192. 
[15] Feldstein, M. (1999). Tax Avoidance and the Deadweight Loss of the Income Tax. Review of Economics and Statistics, 81(4): 674-680.

[16] Firpo, S., N. Fortin and T. Lemieux (2009). Unconditional Quantile Regressions. Econometrica, 77(3): 953-973.

[17] Gelber, A., D. Jones and D.W. Sacks (2020). Estimating Earnings Adjustment Frictions: Method and Evidence from the Earnings Test. American Economic Journal: Applied Economics, 12(1): 1-31.

[18] Gruber, J. and E. Saez (2002). The Elasticity of Taxable Income: Evidence and Implications. Journal of Public Economics, 84: 1-32.

[19] Kleven, H. (2016). Bunching. Annual Review of Economics, 8: 435-464.

[20] Kleven, H. (2019). The EITC and the Extensive Margin: A Reappraisal. NBER Working Paper No. 26405.

[21] Kleven, H. and E. Schultz (2014). Estimating Taxable Income Responses Using Danish Tax Reforms. American Economic Journal: Economic Policy, 6(4): 271-301.

[22] Kleven, H. and M. Waseem (2013). Using Notches to Uncover Optimization Frictions and Structural Elasticities: Theory and Evidence from Pakistan. Quarterly Journal of Economics, 128: 699-723.

[23] Kreiner, C., J. Munch and H. Whitta-Jacobsen (2015). Taxation and the Long Run Allocation of Labor: Theory and Danish Evidence. Journal of Public Economics, 127: $74-86$.

[24] Löffler, M., A. Peichl and S. Siegloch (2018). The Sensitivity of Structural Labor Supply Estimations to Modeling Assumptions. ifo Working Papers 259/2018.

[25] Manning, A. (2003). Monopsony in Motion: Imperfect Competition in Labor Markets. Princeton, NJ: Princeton University Press. 
[26] Neisser, C. (2019). The Elasticity of Taxable Income: A Meta-Regression Analysis. Working Paper.

[27] Saez, E. (1999). Do Taxpayers Bunch at Kink Points? NBER Working Papers 7366.

[28] Saez, E. (2002). Optimal Income Transfer Programs: Intensive Versus Extensive Labor Supply Responses. Quarterly Journal of Economics, 117: 1039-1073.

[29] Saez, E. (2010). Do Taxpayers Bunch at Kink Points? American Economic Journal: Economic Policy, 2(3): 180-212.

[30] Saez, E., J. Slemrod and S. Giertz (2012). The Elasticity of Taxable Income with Respect to Marginal Tax Rates: A Critical Review. Journal of Economic Literature, $50(1): 3-50$.

[31] Slemrod, J. (1998). Methodological Issues in Measuring and Interpreting Taxable Income Elasticities. National Tax Journal, 51(4): 773-788.

[32] Søgaard, J. (2019). Labor Supply and Optimization Frictions: Evidence from the Danish Student Labor Market. Journal of Public Economics, 173: 125-138.

[33] van Soest, A. (1995). Structural Models of Family Labor Supply - a Discrete Choice Approach. Journal of Human Resources, 30(1): 63-88.

[34] Weber, C. (2014). Toward Obtaining a Consistent Estimate of the Elasticity of Taxable Income Using Difference-in-differences. Journal of Public Economics, 117: 90-103. 


\section{Figures}

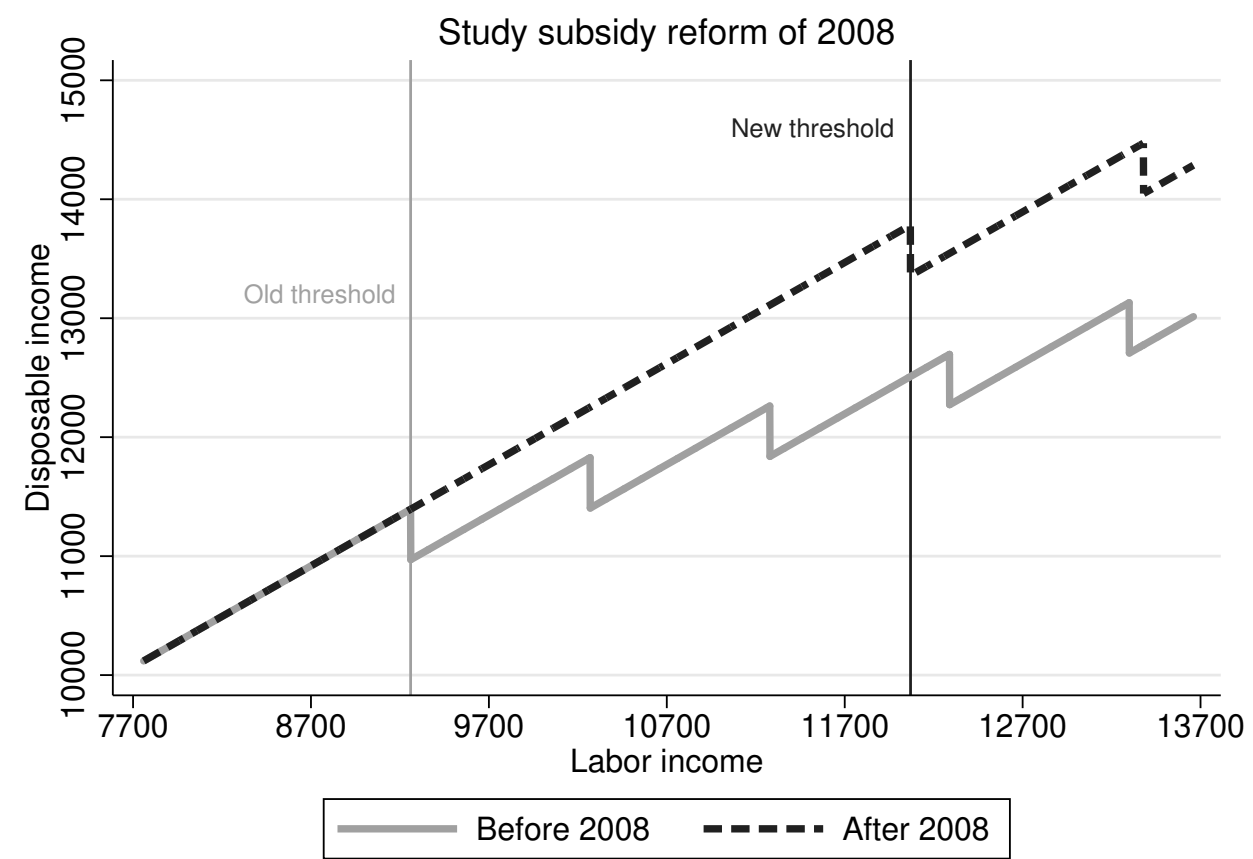

Notes: Figure presents the study subsidy schedule before (gray solid line) and after 2008 (black dashed line) for a student who collects the default 9 subsidy months. The vertical axis denotes disposable income, and horizontal axis labor income. The vertical lines denote the thresholds before (9200 euros) and after (12,070 euros) the 2008 reform. Above the income threshold one month of the study subsidy is reclaimed, resulting in a discontinuous drop in disposable income. Furthermore, an additional month of the subsidy is reclaimed after an additional 1010 and 1310 euros above the threshold before and after 2008 , respectively. The figure illustrates the distinctive change in incentives caused by the increase in the income threshold in 2008, highlighting that the reform encouraged students to increase their earnings above the old income threshold.

Figure 1: Disposable income at different income levels for students with 9 subsidy months in 2007 and 2008 


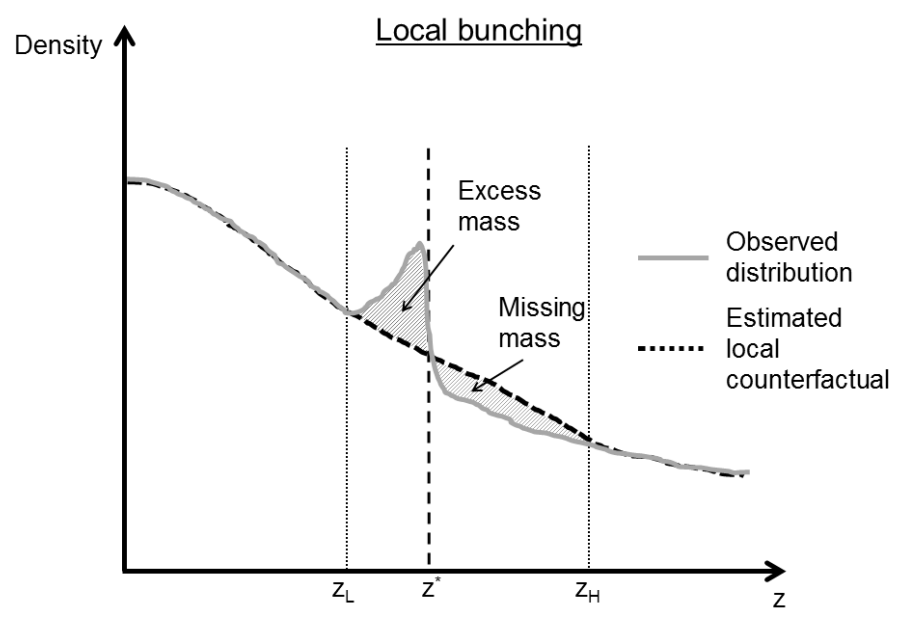

(a) Local bunching

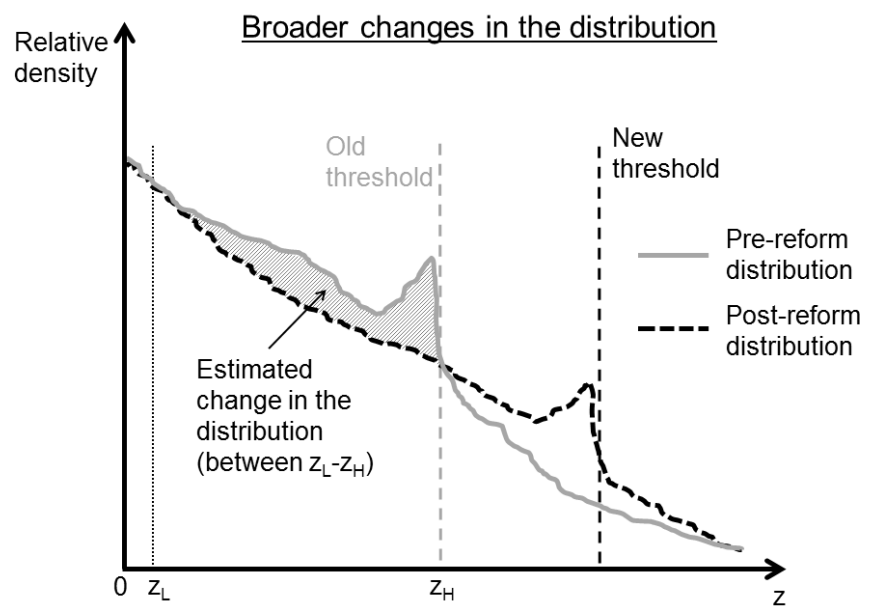

(b) Broader changes in the distribution

Notes: Graph (a) illustrates the excess bunching at the income threshold in a hypothetical earnings (z) distribution (gray solid line), compared to an estimated counterfactual distribution in the absence of the threshold (black dashed line). In the figure, the threshold is denoted by $z^{*}$, and $z_{L}$ and $z_{H}$ denote the lower and upper limits of the bunching region. The counterfactual is estimated by fitting a flexible polynomial function to the observed distribution excluding the area close to the notch between $z_{L}$ and $z_{H}$ from the regression. Excess bunching is estimated by relating the share of individuals in the bunching region $\left(z_{L}, z^{*}\right)$ to the counterfactual density. See Appendix B for more details on the bunching estimation. Graph (b) illustrates broader changes in a hypothetical earnings distribution after an increase in the location of the threshold. The pre-reform distribution is marked with a gray solid line and the post-reform distribution with a black dashed line. $z_{L}$ and $z_{H}$ denote the lower and upper limits of the estimation region. Broader changes in the distribution are estimated by relating the observed relative density before the reform to the relative density after the reform in the income range between the lower and upper limits. See Section 2.3 for more details on the estimation method.

Figure 2: Estimating bunching and broader changes in the earnings distribution 


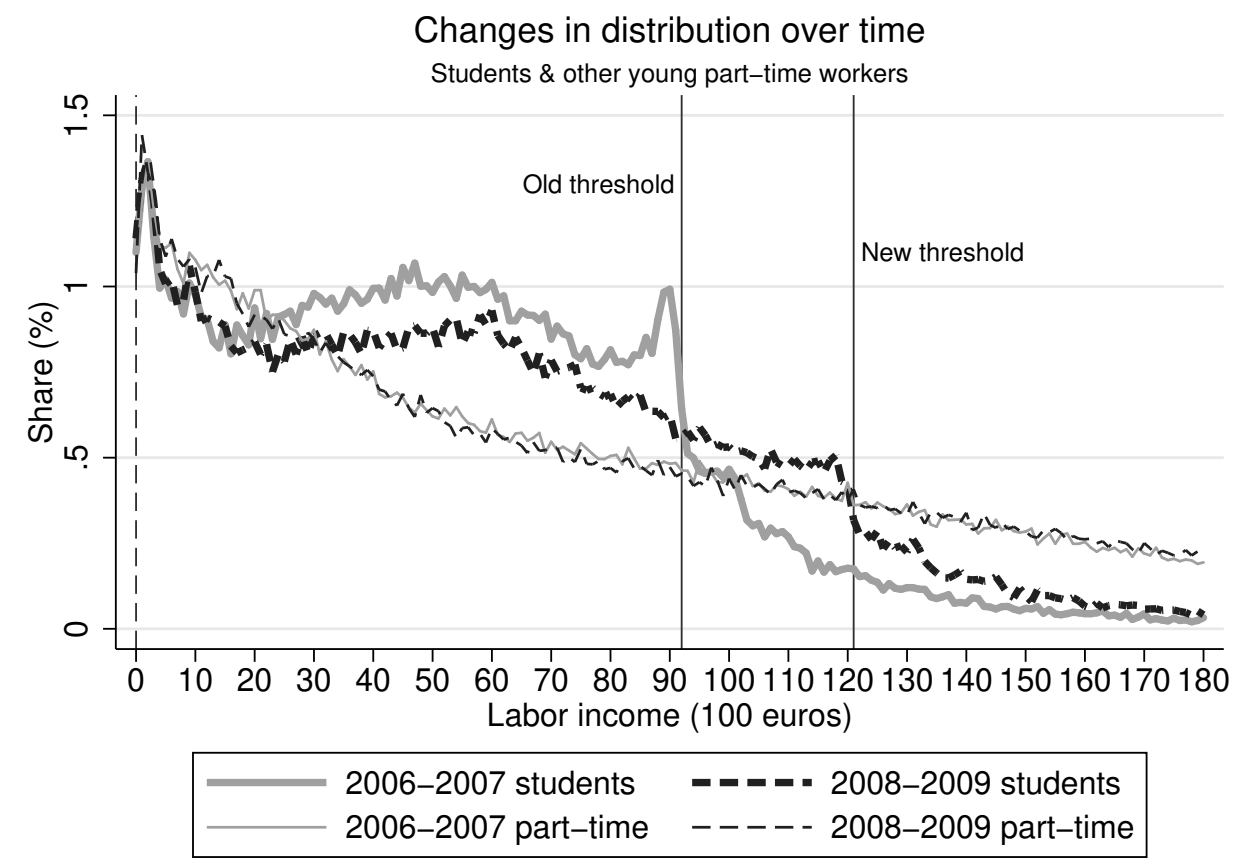

Notes: Figure presents the observed relative earnings distributions before the reform in 2006-2007 (gray solid line) and after the reform in 2008-2009 (black dashed line) within an income range of 0-18,000 euros in bins of 100 euros for students with the default 9 subsidy months in each year, and for young part-time workers who are not students (see Table 2). The first vertical line at 0 denotes the lower limit in the estimation of broader earnings changes in the distribution estimated using equation (2), and the second and third lines denote the pre- and post-reform income thresholds, respectively. The figure illustrates that the earnings distribution after 2008 has a clearly different shape than before the reform, implying that the income threshold affects the shape of the whole labor income distribution, not just the region close to the notch point. The differences-in-differences estimate for broader changes in the distribution within an income range of 0-9200 euros is 9.81 (standard error 1.01). The estimate for broader changes among the student population only is 10.97 (1.85), estimated using equation (1). The bunching estimates at the threshold are $2.93(0.88)$ before and $1.71(0.88)$ after 2008, respectively. A lower limit of 1100 euros below the threshold is used in the bunching estimation both before and after 2008. See Appendix B for a more detailed analysis of bunching responses.

Figure 3: Earnings distributions of students and non-student part-time workers before and after the 2008 reform 


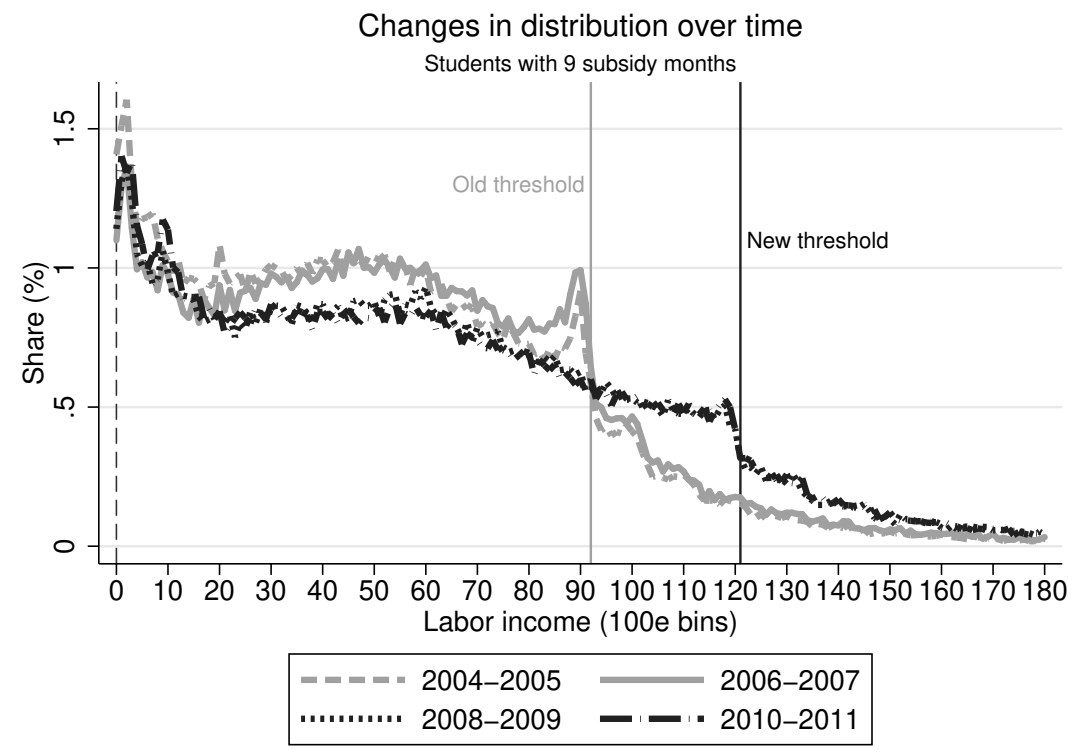

(a) Students

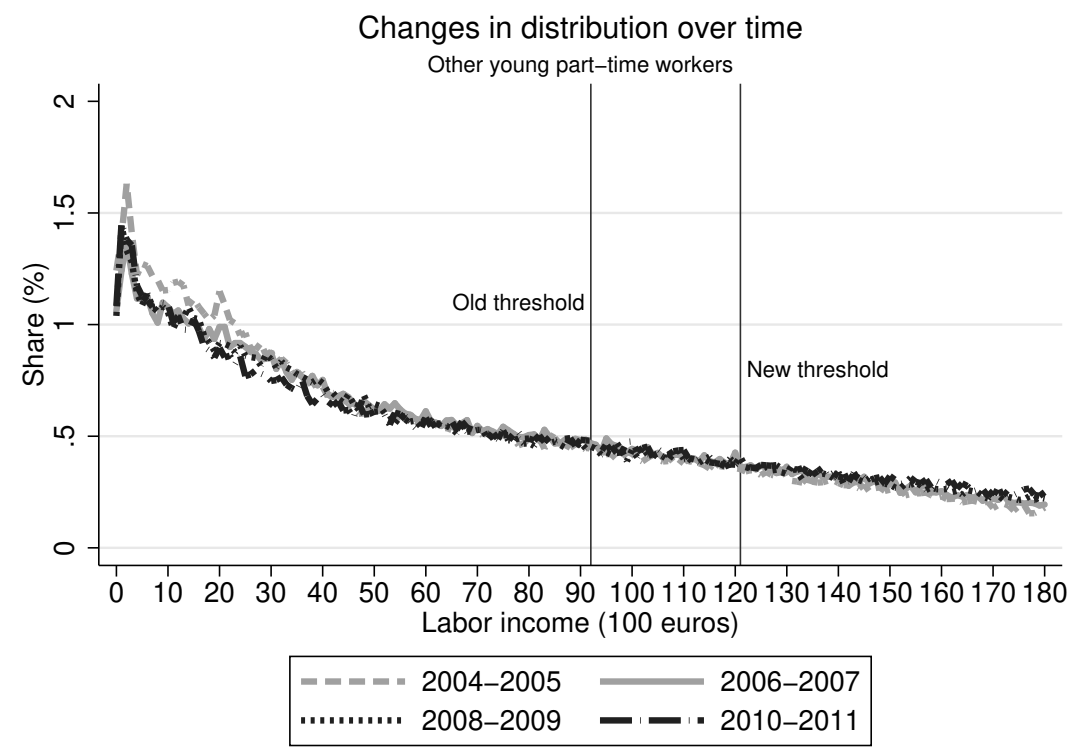

(b) Other young part-time workers

Notes: Figure presents the income distributions of students with 9 subsidy months (graph a) and other young part-time workers (graph b) in 2004-2005 (gray dashed line), 2006-2007 (gray solid line), 2008-2009 (black solid line) and 2010-2011 (black dotted line) within an income range of 0-18,000 euros in bins of 100 euros. The figure shows that the earnings responses of students occurred exactly at the time of the 2008 reform, and that the response is not caused by any gradual changes in the shape of the distribution over time. The distribution for other young part-time workers remained almost unchanged throughout the time period 2004-2011. However, there are similar minor changes at the bottom of distributions of both the treatment and control groups from 2004-2005 to 2006-2007, which further strengthens the case that the distributions develop similarly over time in the absence of the reform.

Figure 4: Income distributions of students and other young part-time workers in $2004-2011$ 


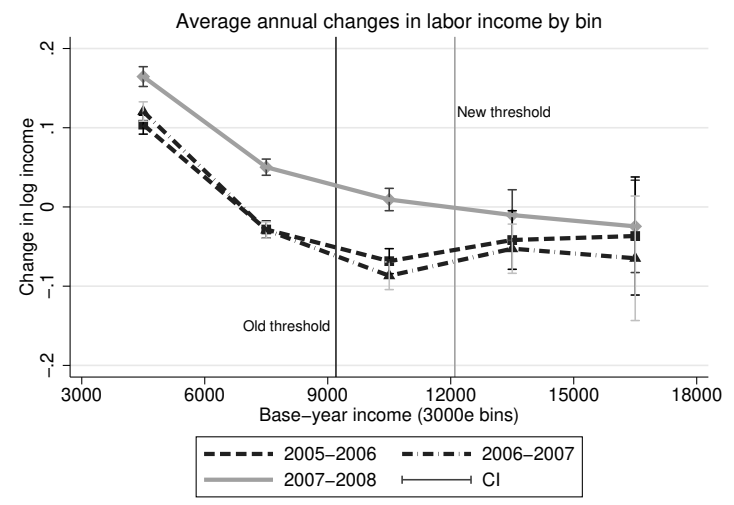

(a) Average changes in labor income

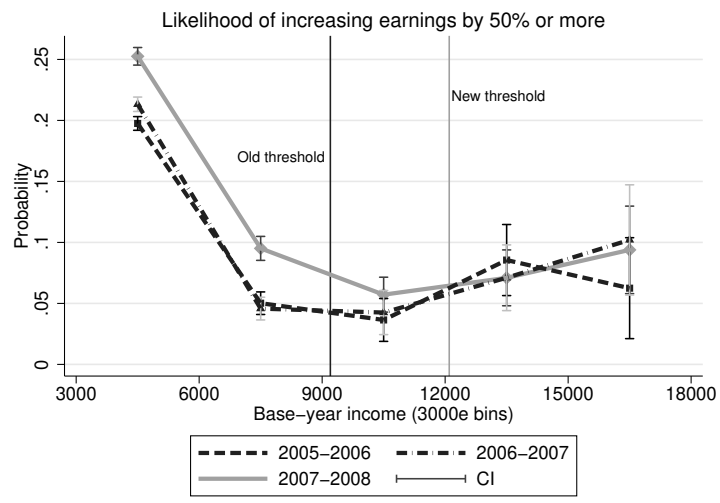

(b) More than $50 \%$ earnings increases

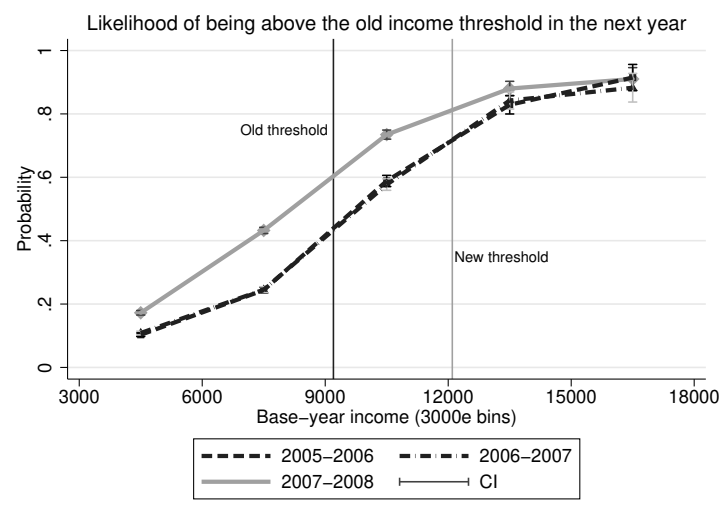

(c) Likelihood of locating above the old income threshold

Notes: Graph (a) presents the average individual-level changes in real log labor income (relative to the 2007 real price index) with 95\% standard errors in base-year bins of 3000 euros for students with 9 subsidy months. Gray solid line represents the years 2007-2008, and black dashed lines the pre-reform years 2005-2006 and 2006-2007. The graph shows that earnings increases are more prevalent below the new threshold at the time of the reform compared to previous years, but there are no significant differences above the new income threshold. Graph (b) presents the average likelihood and $95 \%$ standard errors for increasing labor income by $50 \%$ or more relative to base-year income. The graph illustrates that the likelihood of large income increases is significantly higher below the old threshold at the time of the reform compared to previous years, but there are no significant changes above the old threshold between the years. Graph (c) presents the average likelihood and 95\% standard errors for locating above the old income threshold in the next year. The graph shows that this likelihood increased significantly in bins below the new threshold, but there are no significant changes between the years at larger income levels. Overall, these findings support the view that students responded to the relocation of the notch with large intensive-margin earnings increases instead of marginal earnings adjustments along the whole distribution.

Figure 5: Panel data evidence of individual-level earnings responses 

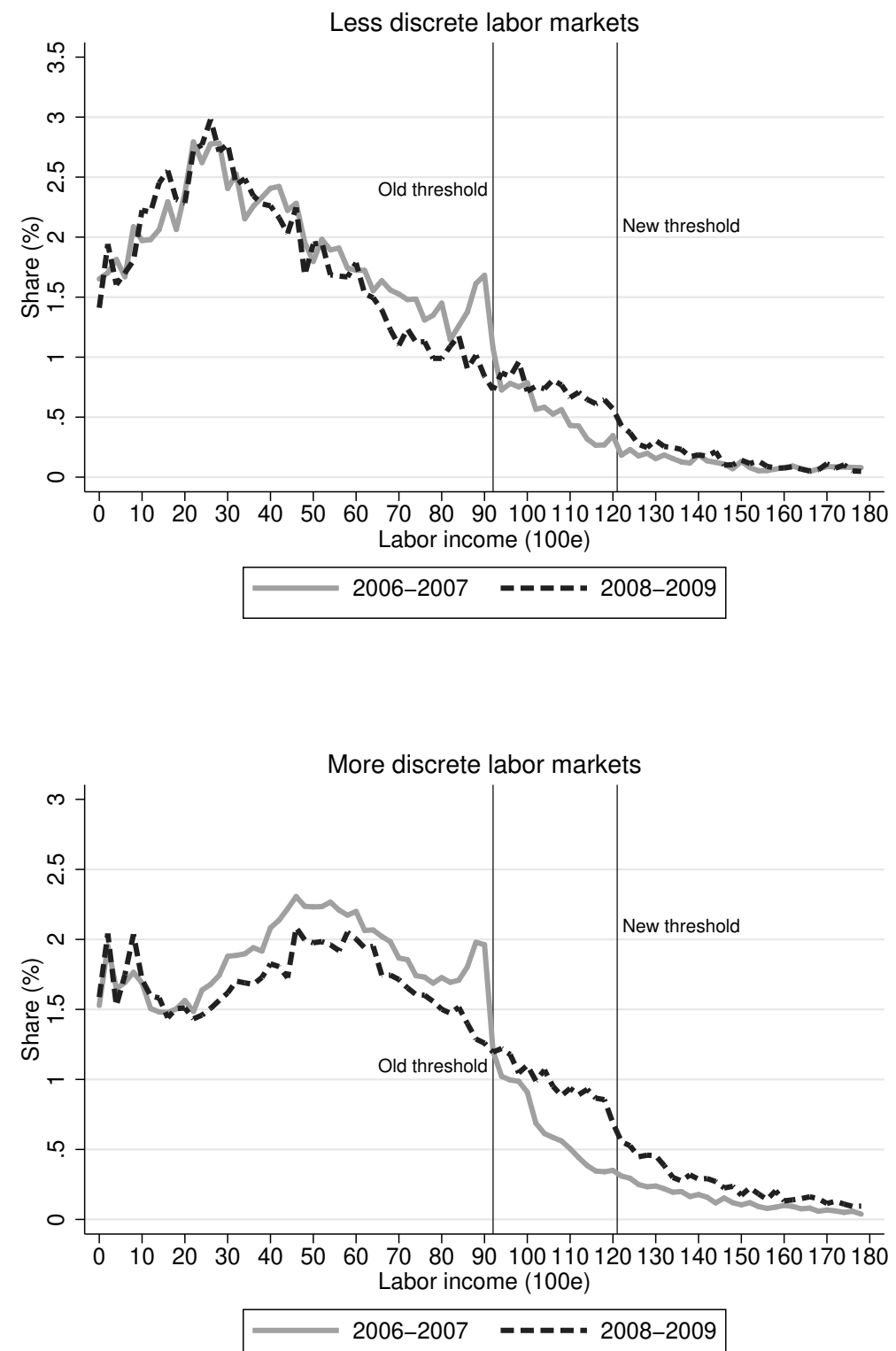

Notes: Figure presents the observed relative earnings distributions before the reform in 2006-2007 (gray solid line) and after the reform in 2008-2009 (black dashed line) within an income range of 0-18,000 euros in bins of 100 euros for students with the default 9 subsidy months in each year working in different types of jobs. Jobs are categorized using firm-level industry classification codes. Less discrete labor markets include restaurants, bars and cafes, cleaning and security services, and retail sales such as supermarkets and gas stations. More discrete labor markets include public sector, and research, manufacturing and construction in the private sector. Using equation (1), the estimate for broader changes in the distribution within an income range of $0-9,200$ euros for the less discrete group is 6.14(1.71), and for the more discrete group 10.94(1.10), illustrating that broader changes in the distribution are significantly more prevalent for the latter group compared to the first group.

Figure 6: Labor income distributions before and after 2008 for students working in less discrete and more discrete labor markets 


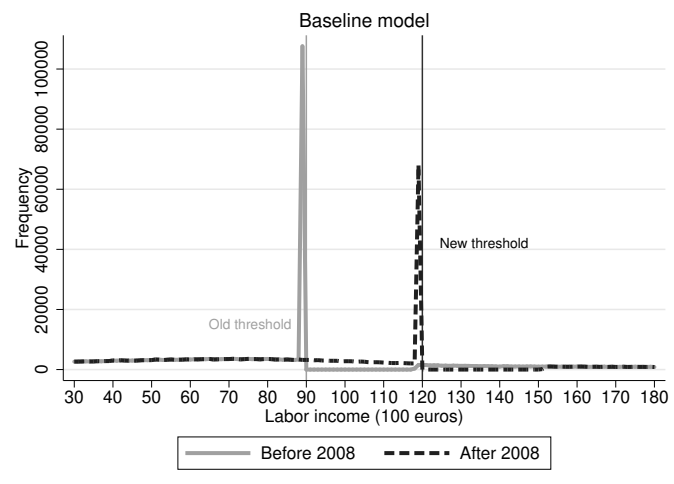

(a) Baseline continuous model

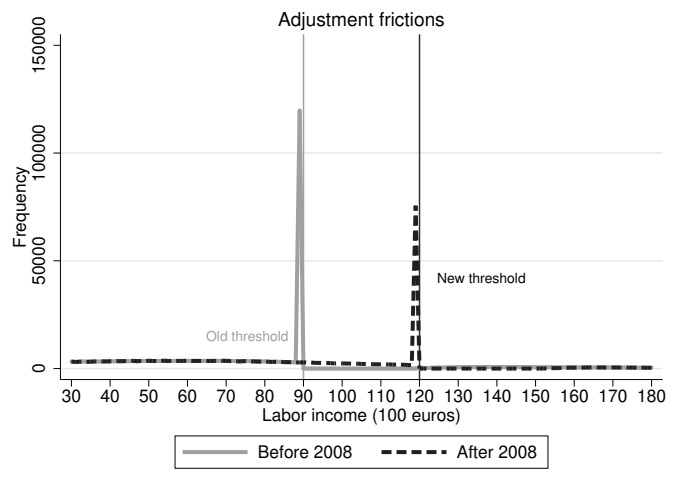

(b) Adjustment frictions

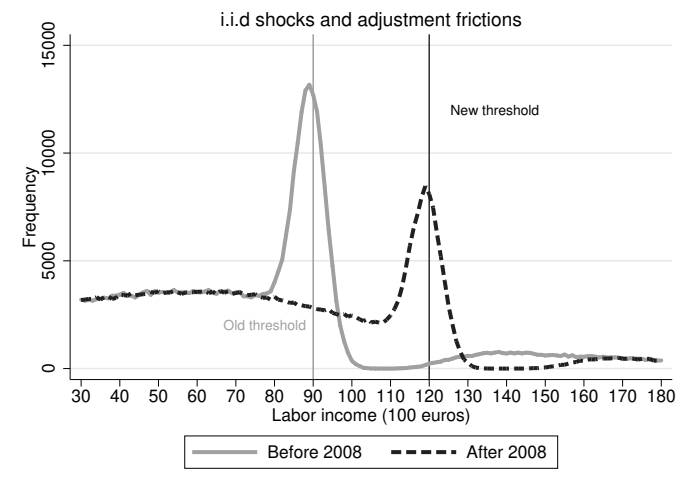

(c) Earnings shocks and adjustment frictions

Notes: Figure presents simulated income distributions before (gray solid line) and after (black dashed line) an increase in the location of the income threshold from 9000 euros to 12,000 euros within an income range of $0-18,000$ euros. The underlying $e$ parameter of 0.2 is used in the simulations. Qualitative results are not sensitive to the choice of this parameter value, except that with higher parameter values the densities above the thresholds reduce. Graph (a) presents the standard continuous-choice model. Graph (b) presents the standard model with adjustment frictions and graph (c) includes both adjustment frictions and unexpected i.i.d shocks in earnings to the standard model. The graphs illustrate that these frictions typically discussed in the literature can induce mitigated and scattered bunching around the threshold, but they do not produce broader changes in the earnings distributions we observed in Figure 3.

Figure 7: Simulated income distributions in the baseline continuous model and with different types of adjustment frictions 

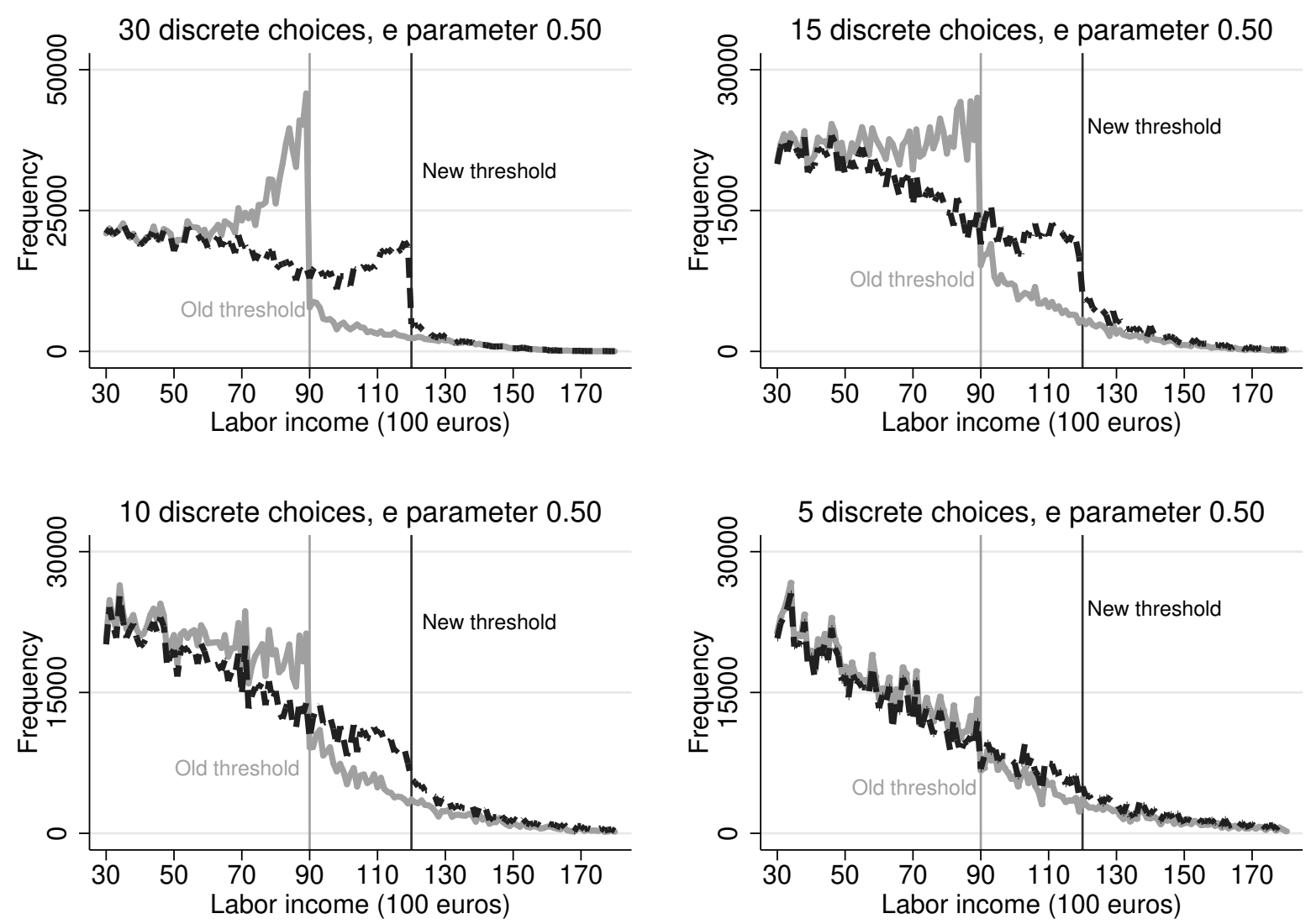

Notes: Figure presents simulated earnings distributions before (gray solid line) and after (black dashed line) an increase in the location of the income threshold from 9000 euros to 12,000 euros within an income range of $0-18,000$ euros using different options for an available discrete earnings choice set. The underlying $e$ parameter of 0.5 is used in the simulations. Using 30 location choices produces distinctive bunching at the threshold, and limited changes in the distribution at lower income levels. In contrast, using 15 or 10 choices produces more limited bunching and more prevalent responses at lower income levels, in a qualitatively similar manner as in Figure 3. However, using only 5 available choices reduces both local responses and broader changes in the distribution, which is inconsistent with our empirical observations.

Figure 8: Simulated income distributions with different discrete choice sets 


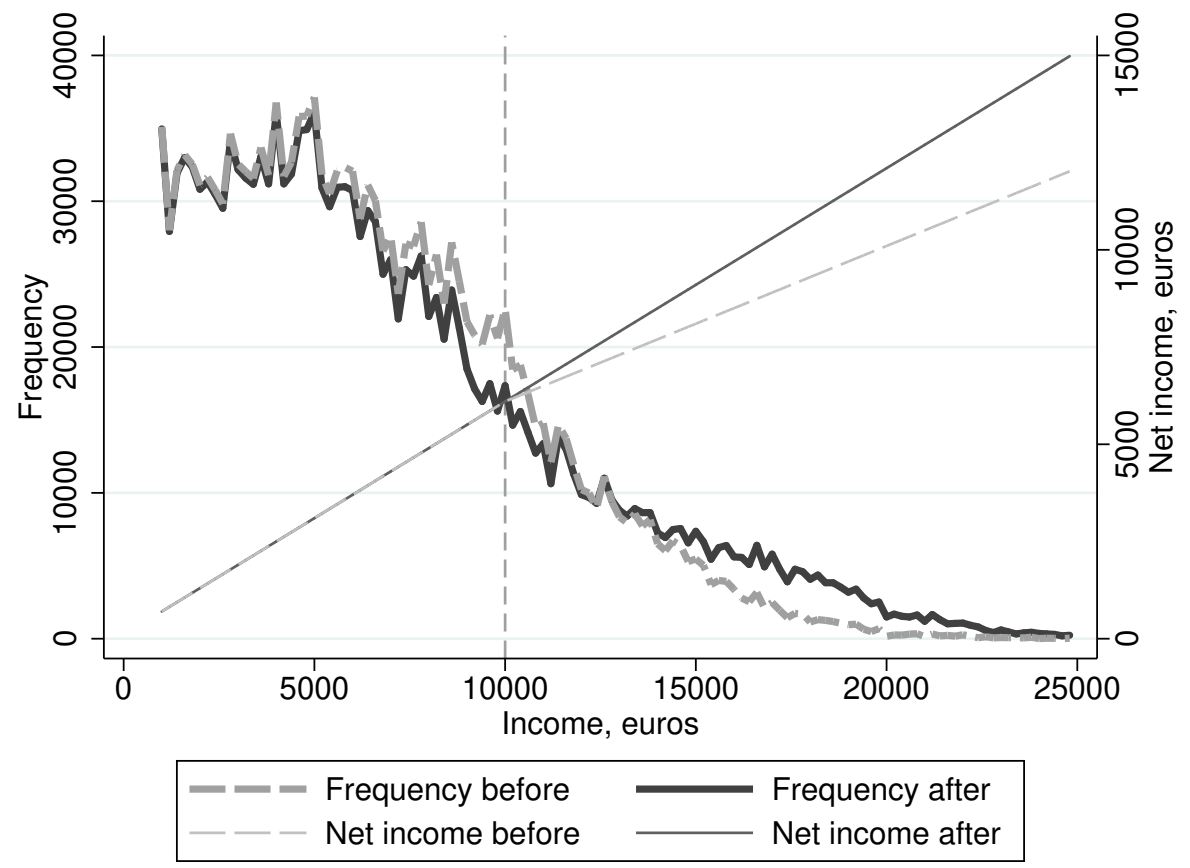

Notes: Figure presents the simulated earnings distributions before (gray dashed line) and after (black solid line) the removal of a tax rate kink at 10,000 euros (dashed vertical line). Horizontal axis denotes pre-reform income, and net income denotes the net-of-tax income (right-hand side vertical axis) before and after the removal of the kink. The marginal tax rate below the kink is $40 \%$ and $60 \%$ above it before the removal of the kink. The underlying $e$ parameter of 0.5 and the assumption of 10 available earnings choices within 0-25,000 euros are used in the simulation.

Figure 9: Simulated income distributions with 10 discrete choices before and after the removal of a tax rate kink 


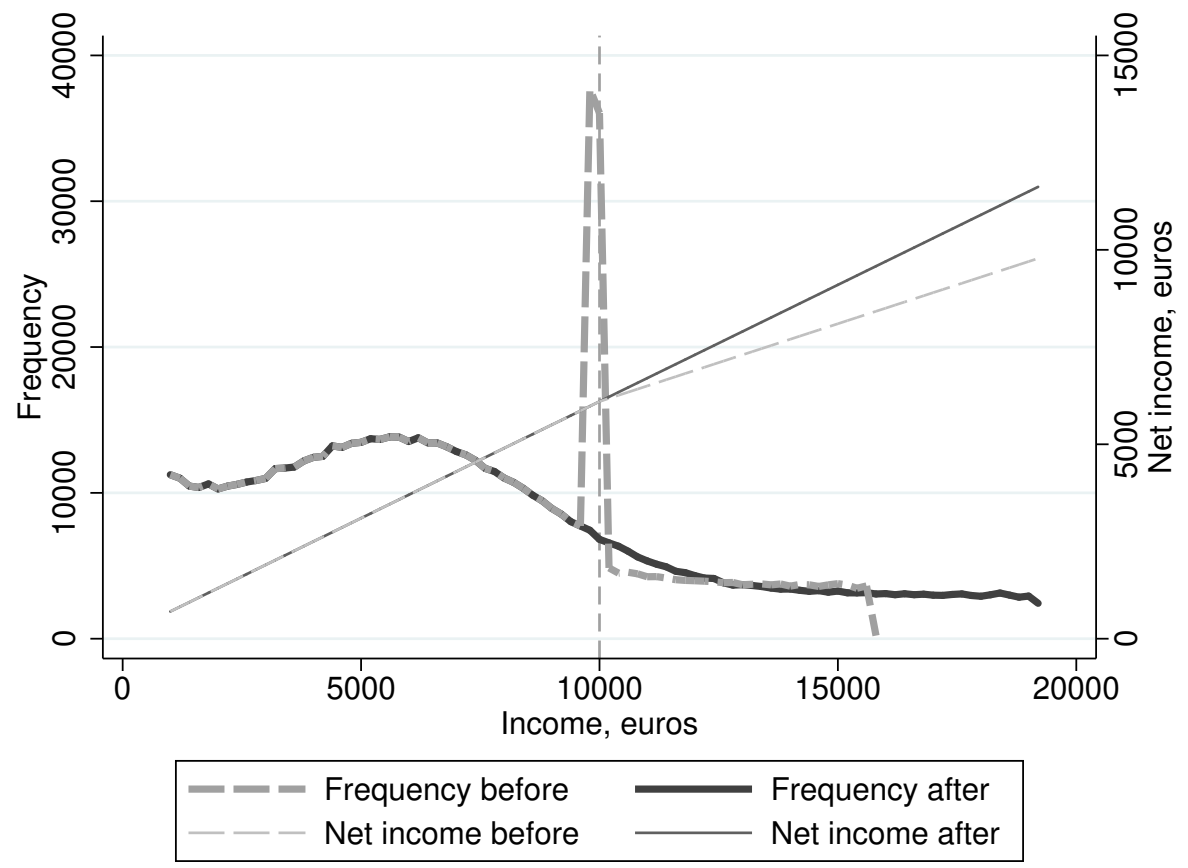

Notes: Figure presents the simulated earnings distributions before (gray dashed line) and after (black solid line) the removal of a tax rate kink at 10,000 euros. Horizontal axis denotes pre-reform income in bins of 200 euros, and net income denotes the net-of-tax income (right-hand side vertical axis) before and after the removal of the kink. The marginal tax rate below the kink is $40 \%$ and $60 \%$ above it before the removal of the kink. The underlying $e$ parameter of 0.5 and the assumption of continuous earnings choices within 0-25,000 euros are used in the simulation.

Figure 10: Simulated income distributions with continuous earnings before and after the removal of a tax rate kink 


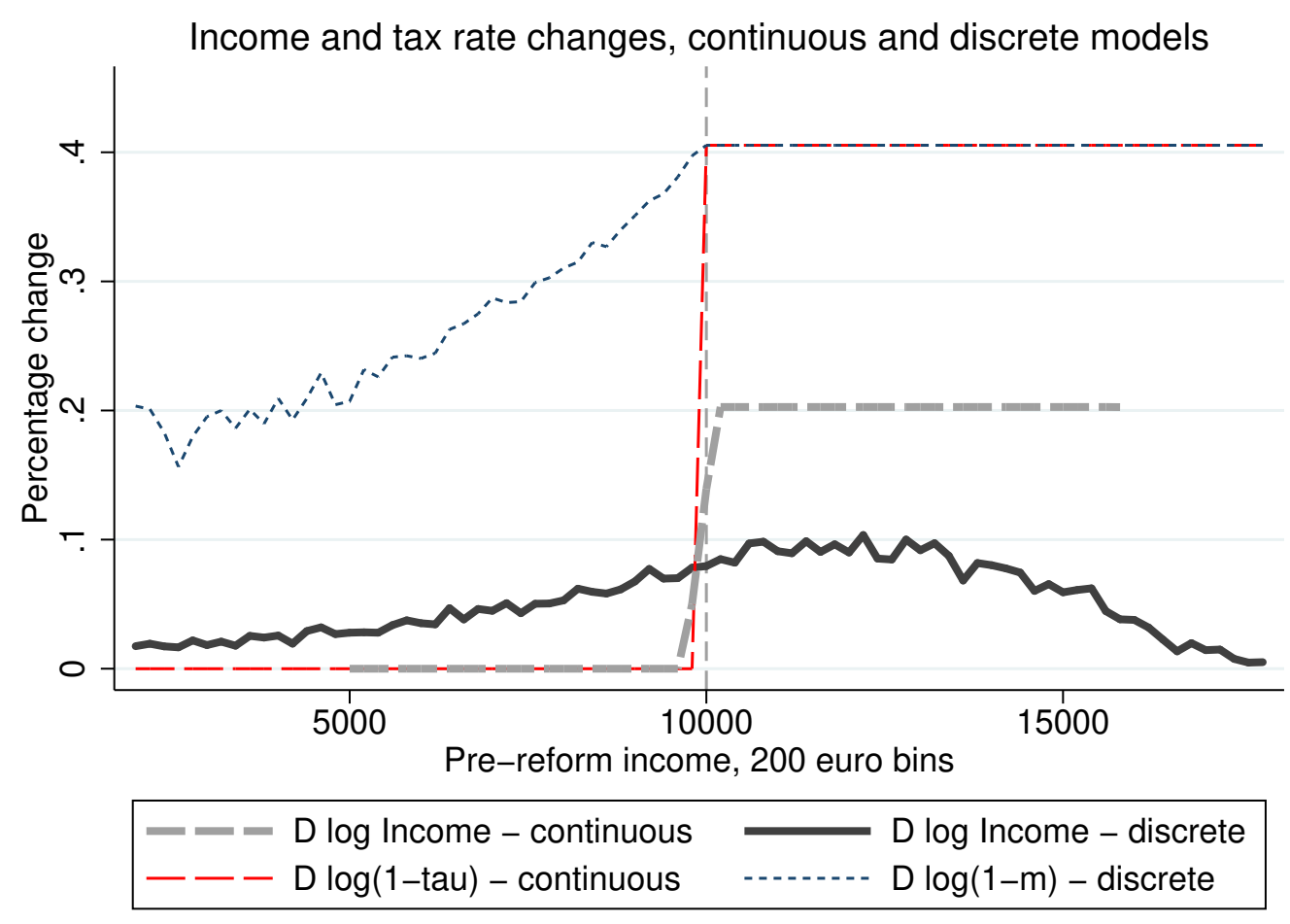

Notes: Figure presents the simulated changes in log income and tax rates for the continuous and discrete models after the removal of a tax rate kink at 10,000 euros using an underlying $e$ parameter of 0.5 . The marginal tax rate below the kink is $40 \%$ and $60 \%$ above it before the removal of the kink. Horizontal axis denotes pre-reform income in bins of 200 euros. Gray dashed line denotes the change in income in the continuous model, and solid black line in the discrete model with 10 available earnings choices within an income range of 0-25,000 euros. Long-dashed red line denotes the change in the net-of-tax rate in the continuous model, and the short-dashed blue line the average change in the average tax rate between the available earnings locations. Based on the assumptions in the continuous model, only individuals with pre-reform income above the original kink point respond to the reform, as only their net-of-tax rate is assumed to be affected by the reform. In the discrete model, a fraction of individuals in income bins below the kink also respond if their next available earnings location is above the original kink. Consequently, the average tax rates are also affected for those individuals below the kink, but the average change is smaller than in the continuous model above the kink. The average change in tax rate in the discrete model equals the average change in the continuous model above the kink by definition. Furthermore, in the baseline continuous model, all individuals are assumed to respond to the reform with a similar earnings response above the kink. In the discrete model, a smaller share of individuals respond with a discrete jump in earnings depending on the locations of the available earnings choices, constituting a smaller average earnings response compared to the continuous model above the kink.

Figure 11: Changes in log income and net-of-tax rate in continuous and discrete models 


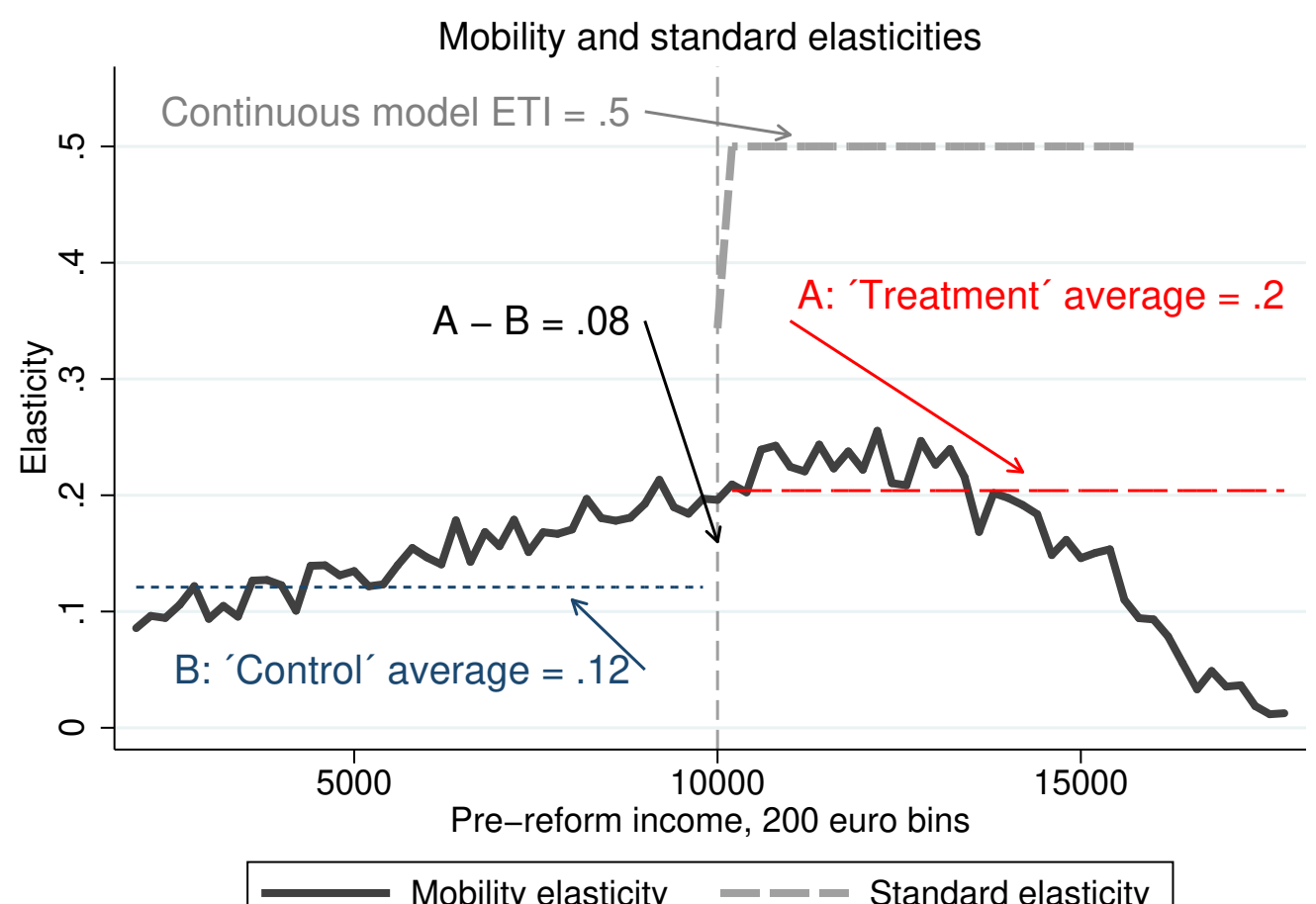

Notes: Figure presents the simulated elasticity estimates associated with the responses to the removal of a tax rate kink at 10,000 euros in the discrete and continuous models using an underlying e parameter of 0.5. The marginal tax rate below the kink is $40 \%$ and $60 \%$ above it before the removal of the kink. Horizontal axis denotes pre-reform income in bins of 200 euros. Solid black line denotes the average binlevel mobility elasticity estimates estimated with 10 available discrete earnings choices. Gray dashed line denotes the standard elasticity estimates from the continuous model. The standard continuous average elasticity estimate is 0.5 above the kink, which exactly equals the assumed e parameter in the model. The average mobility elasticity is 0.14 , and the average estimate is 0.12 below the kink (B) and 0.2 above it (A), on average. These numbers imply that when earnings choices are discrete, the true elasticity estimate can be significantly different from what we would predict based on the canonical continuous model. Also, the figure presents an illustration of the bias in the standard differences-in-differences elasticity estimate when using those below the removed kink as a control group. The standard differences-in-differences approach would simply subtract the elasticity (or earnings responses) below the kink from that above it $(\mathrm{A}-\mathrm{B})$, producing a downward-biased estimate. However, if the underlying earnings responses are continuous, no such bias emerges when using those below the kink (elasticity=0) as a control group.

Figure 12: Elasticity estimates in discrete and continuous models and the bias in the standard differences-in-differences estimate 


\section{Tables}

Table 1: Descriptive statistics, all students 1999-2013

\begin{tabular}{|c|c|c|c|c|}
\hline \multirow[b]{3}{*}{ Mean } & \multicolumn{4}{|c|}{ Individual characteristics } \\
\hline & Age & Female & Labor income & Labor income $>500$ \\
\hline & 23.8 & .58 & 8446 & .80 \\
\hline Median & 23 & 1 & 6306 & 1 \\
\hline sd & 4.23 & .49 & 8197 & .40 \\
\hline \multirow[t]{2}{*}{$\mathrm{N}$} & $2,417,517$ & $2,417,517$ & $2,078,538$ & $2,417,517$ \\
\hline & One employer & Study subsidy months & 9 subsidy months & Years studied \\
\hline Mean & .55 & 8.02 & .42 & 2.2 \\
\hline Median & 1 & 9 & 0 & 2 \\
\hline sd & .50 & 2.64 & .49 & 1.80 \\
\hline \multirow[t]{3}{*}{$\mathrm{N}$} & $1,863,702$ & $2,417,517$ & $2,417,517$ & $2,098,485$ \\
\hline & \multicolumn{4}{|c|}{ Field of industry } \\
\hline & Manufacturing & Hospitality services & Admin. \& Public Sector & Other $/$ missing \\
\hline Mean & .19 & .16 & .39 & .25 \\
\hline sd & .40 & .37 & .49 & .43 \\
\hline \multirow[t]{3}{*}{$\mathrm{N}$} & $2,417,517$ & $2,417,517$ & $2,417,517$ & $2,417,517$ \\
\hline & \multicolumn{4}{|c|}{ Field of study } \\
\hline & Arts \& Humanities & Business \& Soc. Science & Tech., Health \& Soc. Serv. & Other $/$ missing \\
\hline Mean & .17 & .19 & .34 & .29 \\
\hline sd & .38 & .39 & .47 & .42 \\
\hline $\mathrm{N}$ & $2,417,517$ & $2,417,517$ & $2,417,517$ & $2,417,517$ \\
\hline
\end{tabular}

Notes: Table presents the descriptive statistics for all students in 1999-2013, excluding first-year students and those who graduate within a given year. Labor income $>500$ denotes the share of students with annual labor income above 500 euros. One employer denotes the share of students who we observe to work for only one employer within a year among those with information on the employer in the data. 9 subsidy months denotes the share of students with the default study subsidy choice. 
Table 2: Descriptive statistics, non-student part-time workers, 1999-2013

\begin{tabular}{cccccc}
\hline & \multicolumn{5}{c}{ Individual characteristics } \\
Mean & Age & Female & Labor income & Labor income $>500$ & One employer \\
\cline { 2 - 5 } Median & 21 & .56 & 8318 & .93 & .62 \\
sd & 21 & 1 & 6741 & 1 & 1 \\
N & 1.710 & .496 & 7229 & .25 & .48 \\
& 940,786 & 940,786 & 932,572 & 940,786 & 940,786 \\
\cline { 2 - 6 } & \multicolumn{5}{c}{ Field of industry } \\
Mean & .31 & Manufacturing & Hospitality services & Admin. \& Public Sector & Other $/$ missing \\
sd & .46 & .22 & .41 & .06 \\
N & 940,786 & .41 & .49 & .24 \\
\hline
\end{tabular}

Notes: Table presents the descriptive statistics for young, non-student part-time workers used in Figure 3. The group of non-student part-time workers is selected to roughly match students' job and age characteristics. The non-student group comprises individuals who we observe to have less than 12 working months per year in the data, and who are 19-24 years old. The age interval is chosen to match between the 25-75 percentile points of the students' age distribution. Labor income $>500$ denotes the share of individuals with annual labor income above 500 euros. One employer denotes the share of individuals who we observe to work for only one employer within a year among those with information on the employer in the data.

Table 3: Parameter values in the simulation model for the income threshold reform

\begin{tabular}{lc}
\hline Parameter & Value \\
\hline Marginal tax rate $(\tau)$ & \\
Below the notch & 0.22 \\
Above the notch & 0.61 \\
\hline Size of the notch & $500 \mathrm{e}$ \\
\hline Virtual income $(R)$ & \\
Before & $4100 \mathrm{e}$ \\
After & $3600 \mathrm{e}$ \\
\hline Location of the notch (income threshold) & \\
Before & $9000 \mathrm{e}$ \\
After & $12,000 \mathrm{e}$ \\
\hline
\end{tabular}

Notes: Table presents the parameter values used in the simulation model. The parameter values are selected to approximate the actual budget set faced by students under the study subsidy program (see Figure 1]. 
Table 4: Simulated earnings elasticity estimates using different estimation approaches

\begin{tabular}{ccccc}
\hline & $(1)$ & $(2)$ & $(3)$ & $(4)$ \\
Location of the kink & kink 15k & kink 10k & kink 5k & kink 0 \\
\hline Naive ETI & $\mathbf{- 0 . 0 1 5 3}$ & $\mathbf{0 . 0 9 7 8}$ & $\mathbf{0 . 0 8 3 3}$ & - \\
Standard error & $(0.000923)$ & $(0.000839)$ & $(0.000995)$ & \\
Mobility elasticity & $\mathbf{0 . 0 8 1 2}$ & $\mathbf{0 . 1 7 7}$ & $\mathbf{0 . 3 2 0}$ & $\mathbf{0 . 5 5 1}$ \\
Standard error & $(0.000292)$ & $(0.000406)$ & $(0.000563)$ & $(0.000968)$ \\
\hline $\mathrm{N}$ & $3,964,692$ & $3,959,764$ & $3,959,070$ & $4,000,000$ \\
$R^{2}$ & 0.019 & 0.046 & 0.076 & 0.075
\end{tabular}

Notes: Table collects the simulated earnings elasticity estimates using 10 available discrete locations for each individual and an assumed e parameter of 0.5 , and varying the location of the kink. The marginal tax rate below the kink is $40 \%$ and $60 \%$ above it before the removal of the kink. The naive ETI estimates are estimated by regressing the change in the log of earnings on the change in the log of the net-of-tax rate using individuals below the original kink point as a control group for those individuals originally above the kink. In columns (1) and (2), individuals from an income range of 8000 euros below the kink are used as controls, and in column (3) all individuals below the kink are included in the control group. This estimate cannot be measured when the original kink is at zero pre-reform earnings in column (4). The mobility elasticity regresses the observed simulated change in the log income on the change in the net-ofaverage tax rates between the discrete earnings locations. Table shows that the naive ETI estimates are downward-biased compared to the underlying unbiased mobility elasticity estimates, stemming from the fact that a fraction of the control group below the kink also increase their earnings after the simulated reform. Second, the mobility elasticity estimate increases the lower the location of the original kink in the distribution is, as at lower income levels there is, on average, a larger number of available earnings locations above the kink point where individuals can relocate themselves after the reform. 


\section{Appendix A}

\section{Figures}

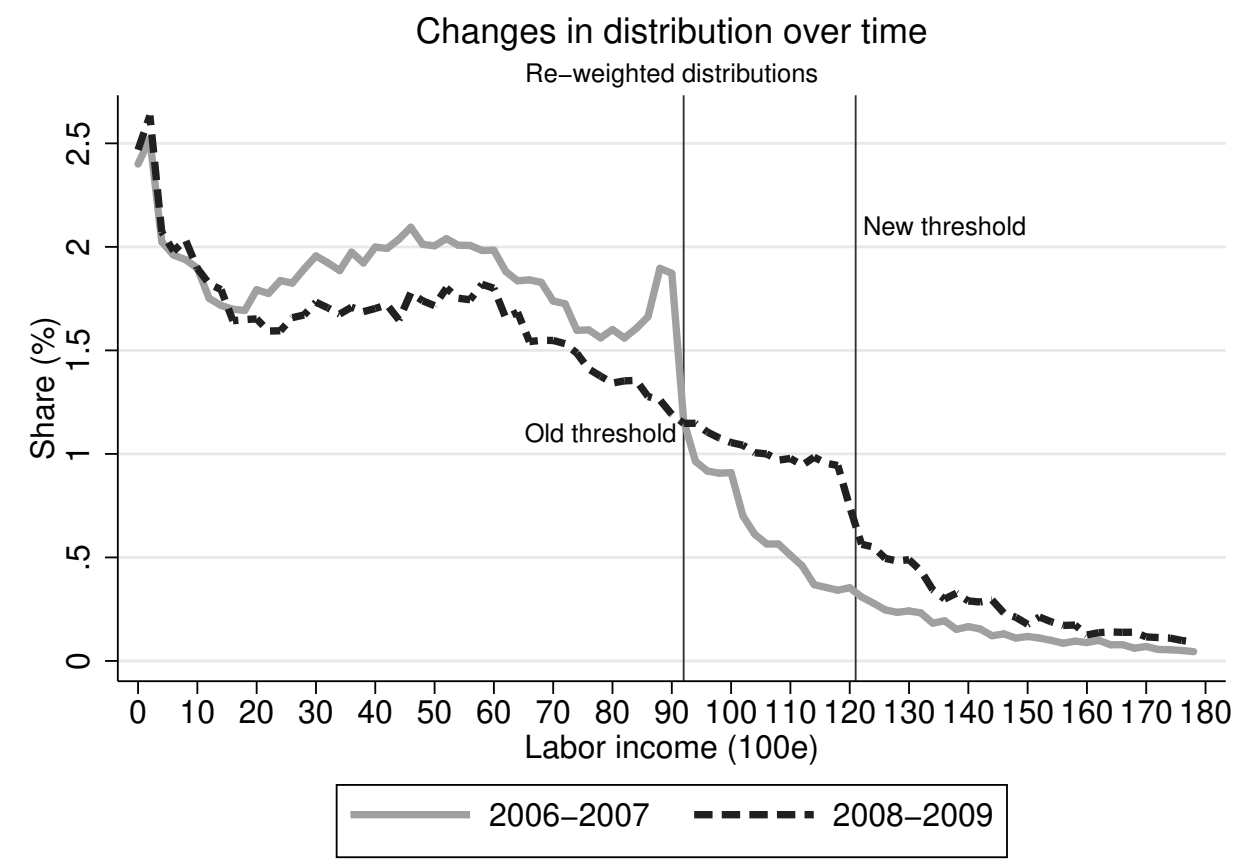

Notes: Figure presents the re-weighted relative earnings distributions before the reform in 2006-2007 (gray solid line) and after the reform in 2008-2009 (black dashed line) within an income range of 0-18,000 euros in bins of 200 euros for students with the default 9 subsidy months in each year. Bin-level inverse probability weighting is used to re-weight the annual distributions using 2006 as the base year. The re-weighting procedure utilizes four groups for both the field of industry and field of study, and three age groups based on age terciles. Using equation (1), the estimate for broader changes in the distribution within an income range of 0-9200 euros is 11.40 (1.01), which is similar to that estimated in the baseline case in Figure 3 in the main text.

Figure A1: Re-weighted income distributions in 2006-2007 and 2008-2009. 


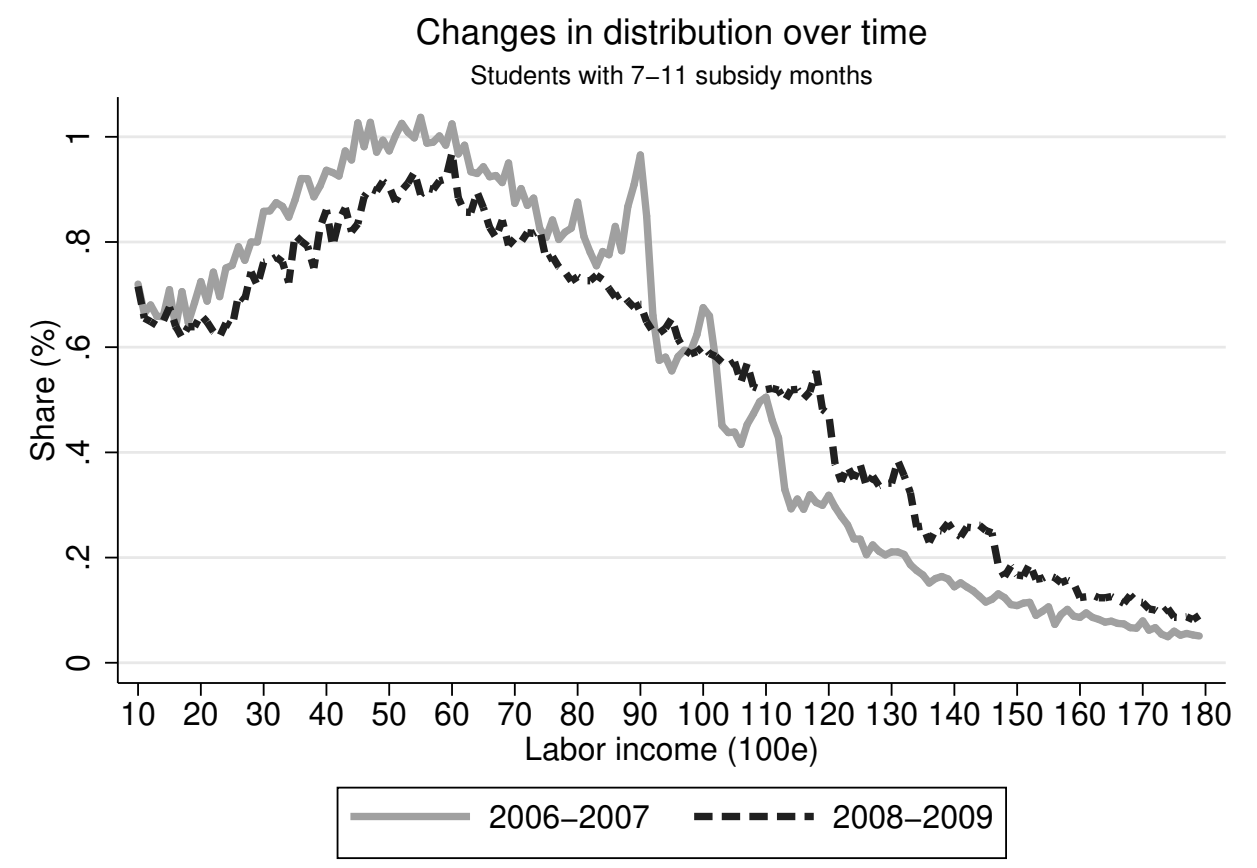

Notes: Figure presents the observed relative earnings distributions before the reform in 2006-2007 (gray solid line) and after the reform in 2008-2009 (black dashed line) within an income range of 0-18,000 euros in bins of 200 euros for students with $7-11$ subsidy months. The figure shows that broader changes in the distribution are prevalent when including students who deviate from the default choice of 9 subsidy months. However, as the number of subsidy months defines the location of the income threshold, changes in the distribution are more scattered over the distribution compared to our baseline case with 9 subsidy months in Figure 3 in the main text. Also, a fraction of students who choose other than 9 subsidy months bunch at their associated income thresholds, which appear as additional spikes in the distribution. Relatedly, as the location of the thresholds both before and after 2008 is not constant in this population, we cannot estimate a measure for broader changes in the distribution for this population following the procedures introduced in Section 2.3

Figure A2: Income distributions in 2006-2007 and 2008-2009, students with 7-11 subsidy months. 


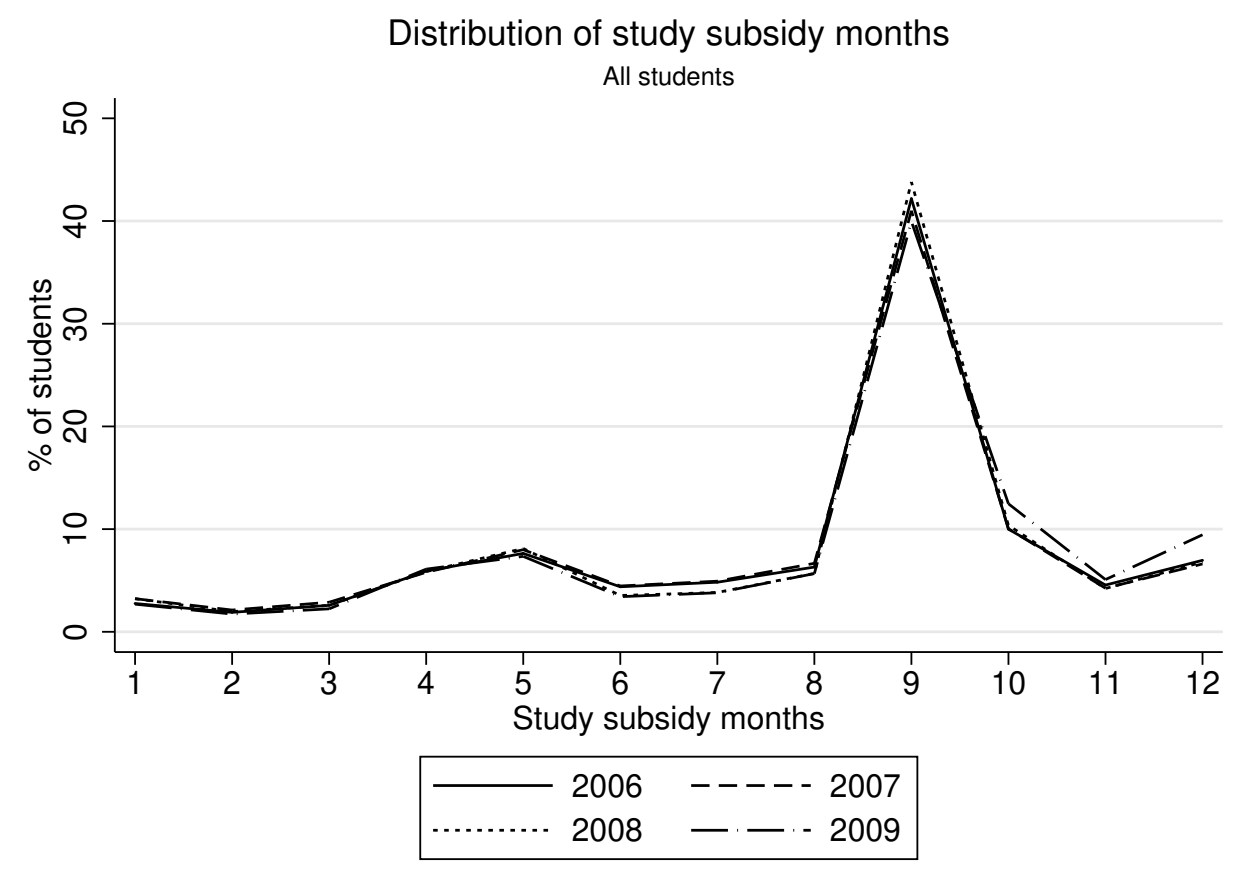

Notes: Figure presents the distribution of study subsidy months in 2006, 2007, 2008 and 2009. In each year, the default 9 months of the subsidy is the most common choice. There are no significant changes in the distribution over time. This indicates that students responded to the reform of 2008 by changing their earnings, but not, on average, by claiming more or less subsidies per year.

Figure A3: Distributions of study subsidy months, 2006-2009. 


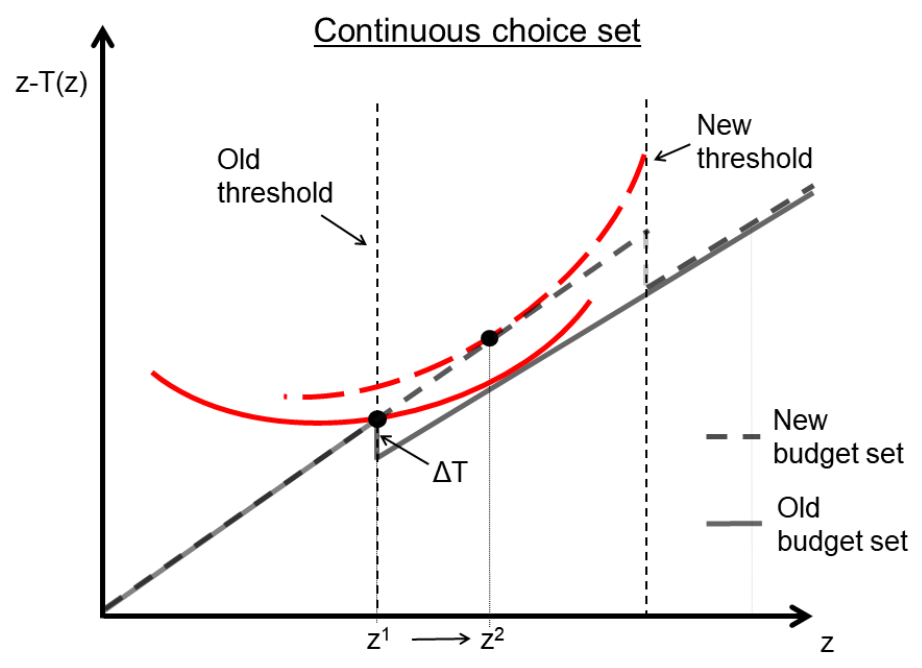

(a) Continuous model

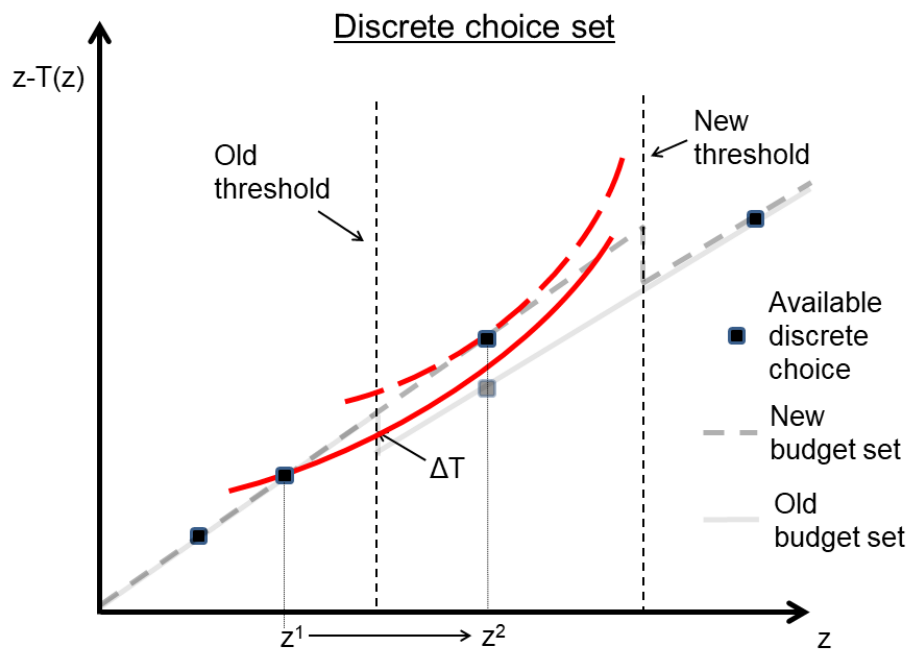

(b) Discrete model

Notes: Figure graphically illustrates the conceptual differences between the continuous and discrete models when an income notch changes its location. The horizontal axis denotes gross earnings $(z)$ and the vertical axis net earnings $(z-T(z))$. In the continuous model in graph (a), the indifference curves are drawn such that an individual would bunch at the original notch, and shifts her location to the right when the location of the notch is increased. By definition, individuals below the original notch are unaffected by the reform. The discrete model in graph (b) includes the same budget set, but the individual now faces a constraint that only certain discrete earnings locations are feasible, marked with black squares in the figure. Under the old location of the notch, the individual would be located in the first possible earnings level below the notch. When the notch is relocated, the next discrete location above the notch becomes more attractive. The main differences between the continuous and discrete models in the figure are that the earnings response is greater in the discrete model and it also occurs from a region below the original notch.

Figure A4: Relocation of the notch in continuous and discrete models 


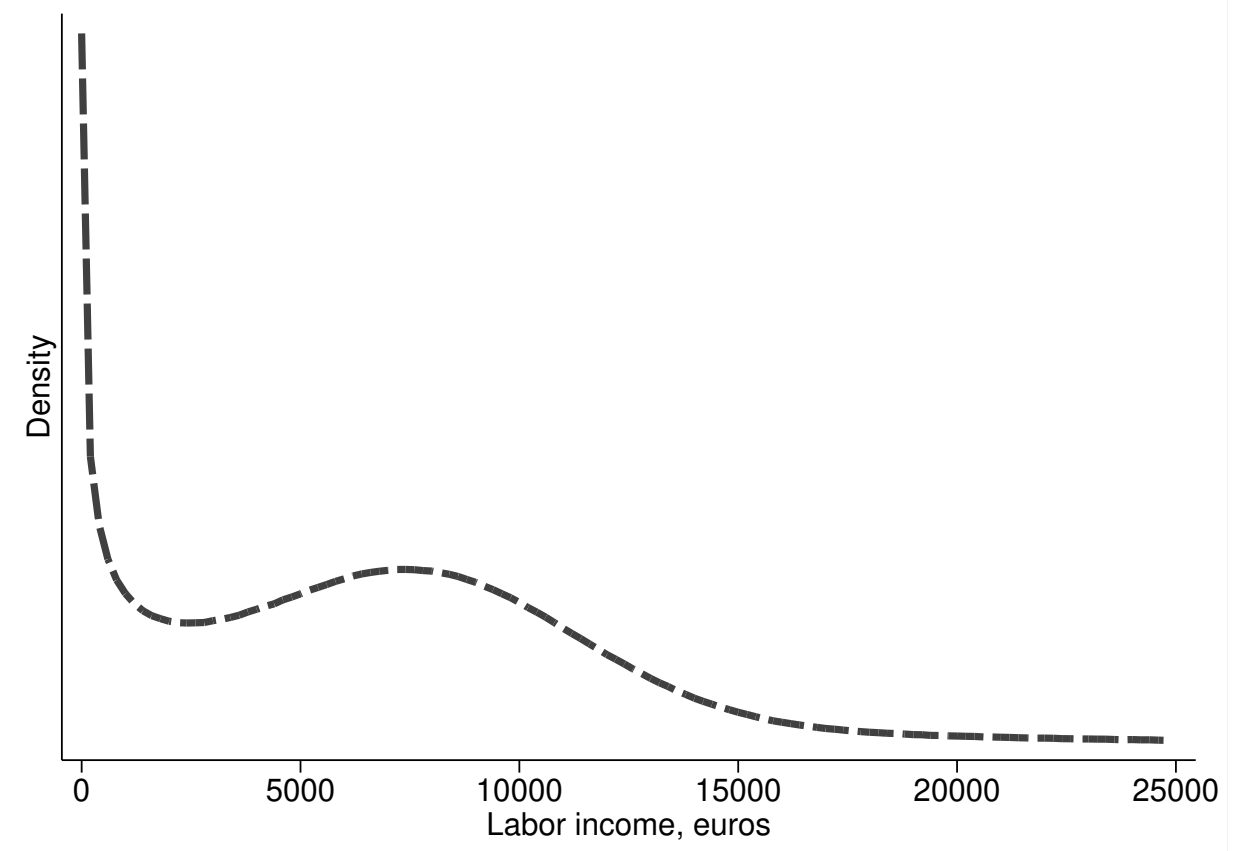

Notes: Figure presents the underlying earnings distribution used in the simulation model. The distribution is a combination of a power distribution and a normal distribution, which delivers an approximate match for the shape of the empirical earnings distribution of students in our empirical analysis. The simulation results are not sensitive to different underlying ability distributions that roughly match the empirical income distribution of students.

Figure A5: Simulated earnings distribution in the absence of taxes 


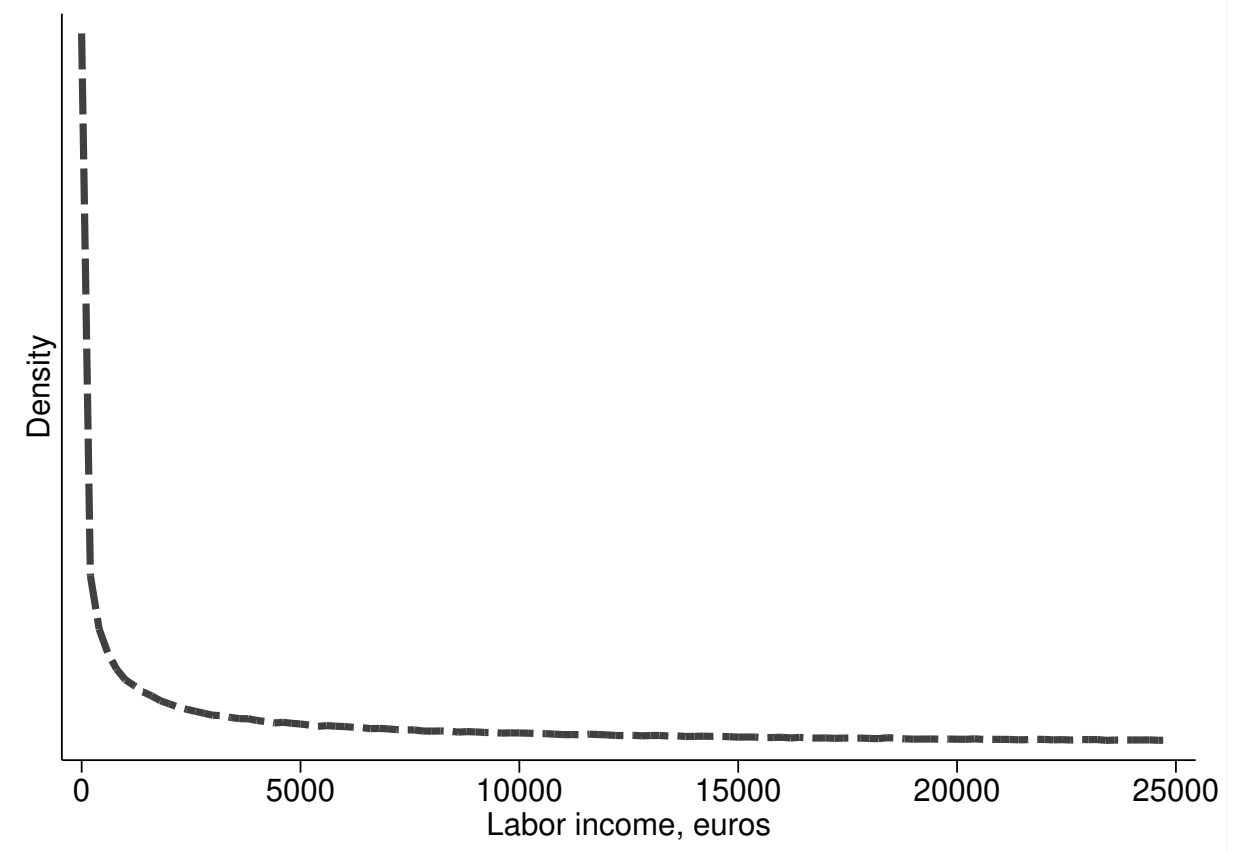

Notes: Figure presents the underlying probability distribution of discrete earnings choices utilized in the discrete choice model simulations. The large mass in the probability distribution at small earnings ensures that each individual has at least one available choice that produces positive utility with positive earnings. The thick tail in the distribution ensures that there is another available choice at a higher income level, although the specific location of this choice can vary across different draws. In the simulation procedure, we iterate the model multiple times, and in each round draw new available earnings choices. The resulting earnings distribution for the full population is continuous, although one individual faces only a discrete and limited number of available choices.

Figure A6: Probability distribution of discrete earnings choices 


\section{Tables}

Table A1: Income thresholds before and after the 2008 reform

\begin{tabular}{|c|c|c|c|c|}
\hline & Before 2008 (academic year 2006/2007) & After 2008 (academic year 2008/2009) \\
\hline Study subsidy months & Income threshold & $\begin{array}{c}\text { Relative income } \\
\text { loss at the margin } \\
\text { if the threshold is } \\
\text { exceeded }\end{array}$ & $\begin{array}{c}\text { Income threshold } \\
\text { Relative income } \\
\text { loss at the margin } \\
\text { the threshold is } \\
\text { exceeded }\end{array}$ \\
\hline 1 & 17,340 & $3.1 \%$ & 22,550 & $2.5 \%$ \\
2 & 16,330 & $3.2 \%$ & 21,190 & $2.7 \%$ \\
3 & 15,320 & $3.5 \%$ & 19,930 & $2.9 \%$ \\
4 & 14,310 & $3.7 \%$ & 18,620 & $3.1 \%$ \\
5 & 13,300 & $4.0 \%$ & 17,310 & $3.3 \%$ \\
6 & 12,290 & $4.3 \%$ & 16,000 & $3.6 \%$ \\
7 & 11,280 & $4.7 \%$ & 14,690 & $3.9 \%$ \\
8 & 10,270 & $5.2 \%$ & 13,380 & $4.3 \%$ \\
$\mathbf{9}$ & $\mathbf{9 2 6 0}$ & $\mathbf{5 . 7 \%}$ & $1 \mathbf{1 2}, \mathbf{0 7 0}$ & $\mathbf{4 . 8 \%}$ \\
10 & 8250 & $6.4 \%$ & 9450 & $5.3 \%$ \\
11 & 7240 & $7.3 \%$ & 8140 & $6.1 \%$ \\
12 & 6230 & $8.5 \%$ & & $7.1 \%$ \\
\hline
\end{tabular}

Note: Table presents the annual income thresholds in euros for different subsidy months before and after the 2008 reform. The highlighted 9 months of the subsidy is the default choice. The relative income loss from marginally exceeding the income threshold is calculated using the full study subsidy (461 euros and 500 euros before and after 2008, respectively) plus $15 \%$ interest collected by the Social Insurance Institution if the subsidy is reclaimed due to exceeding the income threshold.

Table A2: Variables used in the mobility elasticity estimation for students

\begin{tabular}{ccccc}
\hline & $\begin{array}{c}\text { Avg. gross earnings } \\
(2000-18,000 \mathrm{e})\end{array}$ & $\begin{array}{c}\text { Avg. net income below notch } \\
(2000-9300 \mathrm{e})\end{array}$ & $\begin{array}{c}\text { Avg. net income above notch } \\
(9300-18,000)\end{array}$ & $\begin{array}{c}\text { Differences in net incomes } \\
\text { between avg. locations }\end{array}$ \\
\hline 2007 & 7116 & 8693 & 12,173 & 3534 \\
2008 & 7529 & 8785 & 13,592 & 4807 \\
& & Gross earnings below: 6008 & Gross earnings above: 11,821 & \\
\hline
\end{tabular}

Notes: Table presents the variables used when calculating the mobility elasticity estimate for students in Section 4.2 in the main text. Mobility elasticity is measured by relating the log change in average gross earnings to the log change in the difference in net income between the two average earnings locations below and above the original notch. Net earnings are calculated using the SISU microsimulation model. 
Table A3: Simulated earnings elasticity estimates using different discrete earnings choices and the original kink point at 5000 euros

\begin{tabular}{cccccc}
\hline & $(1)$ & $(2)$ & $(3)$ & $(4)$ & $(5)$ \\
\# of discrete choices & 5 & 10 & 15 & 20 & 30 \\
\hline Naive ETI & $\mathbf{- 0 . 1 3 3}$ & $\mathbf{0 . 0 8 3 3}$ & $\mathbf{0 . 1 9 7}$ & $\mathbf{0 . 2 6 3}$ & $\mathbf{0 . 3 3 7}$ \\
Standard error & $(0.0017)$ & $(0.0001)$ & $(0.0008)$ & $(0.0006)$ & $(0.0005)$ \\
Mobility elasticity & $\mathbf{0 . 2 7 3}$ & $\mathbf{0 . 3 2 0}$ & $\mathbf{0 . 3 5 6}$ & $\mathbf{0 . 3 7 5}$ & $\mathbf{0 . 4 0 2}$ \\
Standard error & $(0.00096)$ & $(0.0006)$ & $(0.000434)$ & $(0.0004)$ & $(0.0003)$ \\
\hline $\mathrm{N}$ & $3,886,794$ & $3,959,070$ & $3,980,080$ & $3,988,928$ & $3,995,258$ \\
$R^{2}$ & 0.020 & 0.076 & 0.145 & 0.218 & 0.371 \\
\hline
\end{tabular}

Notes: Table collects the simulated earnings elasticity estimates using different available discrete earnings locations for each individual $(5,10,15,20,30)$ and an assumed $e$ parameter of 0.5 . The marginal tax rate below the kink is $40 \%$ and $60 \%$ above it before the removal of the kink located at 5000 euros. The naive ETI estimates are estimated by regressing the change in the log of earnings on the change in the $\log$ of the net-of-tax rate using individuals below the original kink point as a control group for those individuals originally above the kink. The mobility elasticity regresses the observed simulated change in the log income on the change in the net-of-average tax rates between the discrete earnings locations.

Table A4: Simulated earnings elasticity estimates using different discrete earnings choices and the original kink point at 10,000 euros

\begin{tabular}{cccccc}
\hline & $(1)$ & $(2)$ & $(3)$ & $(4)$ & $(5)$ \\
\# of discrete choices & 5 & 10 & 15 & 20 & 30 \\
\hline Naive ETI & $\mathbf{- 0 . 0 1 1}$ & $\mathbf{0 . 0 9 7 8}$ & $\mathbf{0 . 1 9 0}$ & $\mathbf{0 . 2 5 0}$ & $\mathbf{0 . 3 1 9}$ \\
Standard error & $(0.0010)$ & $(0.0008)$ & $(0.0007)$ & $(0.0006)$ & $(0.0004)$ \\
Mobility elasticity & $\mathbf{0 . 1 2 8}$ & $\mathbf{0 . 1 7 7}$ & $\mathbf{0 . 2 1 4}$ & $\mathbf{0 . 2 3 9}$ & $\mathbf{0 . 2 8 1}$ \\
Standard error & $(0.0006)$ & $(0.0004)$ & $(0.0003)$ & $(0.0003)$ & $(0.0002)$ \\
\hline $\mathrm{N}$ & $3,885,732$ & $3,959,764$ & $3,980,158$ & $3,988,936$ & $3,995,260$ \\
$R^{2}$ & 0.010 & 0.046 & 0.100 & 0.163 & 0.301
\end{tabular}

Notes: Table collects the simulated earnings elasticity estimates using different available discrete earnings locations for each individual $(5,10,15,20,30)$ and an assumed $e$ parameter of 0.5 . The marginal tax rate below the kink is $40 \%$ and $60 \%$ above it before the removal of the kink located at 10,000 euros. The naive ETI estimates are estimated by regressing the change in the log of earnings on the change in the $\log$ of the net-of-tax rate using individuals below the original kink in an income range of 8000 euros below the kink as a control group for those individuals originally above the kink. The mobility elasticity regresses the observed simulated change in the log income on the change in the net-of-average tax rates between the discrete earnings locations. 
Table A5: Simulated earnings elasticity estimates using different discrete earnings choices and the original kink point at 15,000 euros

\begin{tabular}{cccccc}
\hline & $(1)$ & $(2)$ & $(3)$ & $(4)$ & $(5)$ \\
\# of discrete choices & 5 & 10 & 15 & 20 & 30 \\
\hline Naive ETI & $\mathbf{- 0 . 0 2 8 9}$ & $\mathbf{- 0 . 0 1 5 3}$ & $\mathbf{0 . 0 1 9 4}$ & $\mathbf{0 . 0 5 8 6}$ & $\mathbf{0 . 1 3 0}$ \\
Standard error & $(0.0009)$ & $(0.0009)$ & $(0.0009)$ & $(0.0008)$ & $(0.0006)$ \\
Mobility elasticity & $\mathbf{0 . 0 5 8 0}$ & $\mathbf{0 . 0 8 1 2}$ & $\mathbf{0 . 0 9 8 7}$ & $\mathbf{0 . 1 1 5}$ & $\mathbf{0 . 1 4 3}$ \\
Standard error & $(0.0005)$ & $(0.0003)$ & $(0.0002)$ & $(0.0002)$ & $(0.0002)$ \\
\hline $\mathrm{N}$ & $3,907,916$ & $3,964,692$ & $3,981,306$ & $3,989,246$ & $3,995,290$ \\
$R^{2}$ & 0.004 & 0.019 & 0.041 & 0.074 & 0.159
\end{tabular}

Notes: Table collects the simulated earnings elasticity estimates using different available discrete earnings locations for each individual $(5,10,15,20,30)$ and an assumed $e$ parameter of 0.5 . The marginal tax rate below the kink is $40 \%$ and $60 \%$ above it before the removal of the kink located at 10,000 euros. The naive ETI estimates are estimated by regressing the change in the log of earnings on the change in the $\log$ of the net-of-tax rate using individuals below the original kink in an income range of 8000 euros below the kink as a control group for those individuals originally above the kink. The mobility elasticity regresses the observed simulated change in the log income on the change in the net-of-average tax rates between the discrete earnings locations. 


\section{Appendix B}

\section{Bunching estimation.}

Behavioral responses to local discontinuous changes in the budget set, such as tax rate kinks or notches, are predominantly estimated in the recent literature using a bunching methodology (see Kleven (2016) for a summary). Intuitively, if a discontinuous jump in incentives affects earnings, we should find an excess mass of individuals located just below the threshold in the earnings distribution. The excess bunching thus captures the earnings distortions created by the threshold in the absence of optimization frictions and when earnings choices are continuous. Saez (2010) and Kleven and Waseem (2013) show that under certain restrictions and within the continuous labor supply model, the bunching estimate can be translated into an average earnings elasticity, representing a relevant parameter for the welfare analysis of taxes and income transfers.

We measure local responses to the notch caused by the income threshold following the bunching method presented in Kleven and Waseem (2013). The local counterfactual density is estimated by fitting a flexible polynomial function to the observed distribution, excluding an area around the study subsidy income threshold $z^{*}$ from the observed income distribution. We group students into income bins of 100 euros and then estimate a counterfactual density by excluding the region $\left[z_{L}, z_{H}\right]$ around the threshold from the regression:

$$
c_{j}=\sum_{i=0}^{p} \beta_{i}\left(z_{j}\right)^{i}+\sum_{i=z_{L}}^{z_{H}} \eta_{i} \cdot \mathbf{1}\left(z_{j}=i\right)+\varepsilon_{j}
$$

where $c_{j}$ is the count of individuals in bin $j$, and $z_{j}$ denotes the income level in bin $j$. The order of the polynomial is denoted by $p$. Thus the fitted values for the counterfactual density are given by $\hat{c}_{j}=\sum_{i=0}^{p} \beta_{i}\left(z_{j}\right)^{i}$. The excess bunching is then estimated by relating the actual number of students close to the threshold within $\left(z_{L}, z^{*}\right)$ to the estimated counterfactual density in the same region:

$$
\hat{b}\left(z^{*}\right)=\frac{\sum_{i=z_{L}}^{z^{*}}\left(c_{j}-\hat{c}_{j}\right)}{\sum_{i=z_{L}}^{z^{*}} \hat{c}_{j} / N_{j}}
$$

where $N_{j}$ is the number of bins within $\left[z_{L}, z^{*}\right]$.

Following Kleven and Waseem (2013), we set the lower limit of the excluded region $\left(z_{L}\right)$ based on visual observations of the income distribution to represent the point in the distribution where the bunching behavior begins, i.e. when the density begins to increase. We determine $z_{H}$ such that the estimated excess mass, $\hat{b}_{E}\left(z^{*}\right)=\left(\sum_{i=z_{L}}^{z^{*}} c_{j}-\hat{c}_{j}\right)$, equals the estimated missing mass above the threshold, $\hat{b}_{M}\left(z^{*}\right)=\left(\sum_{i=z>z^{*}}^{z_{H}} \hat{c}_{j}-c_{j}\right)$, stemming from individuals who would locate above the income threshold in the absence of it and who respond to the notch by bunching below it, illustrated in Figure 2 in the main text. We apply this convergence condition by starting from a small value of $z_{H}$ and increasing it gradually until $\hat{b}_{E}\left(z^{*}\right) \approx \hat{b}_{M}\left(z^{*}\right)$. This convergence condition also defines the marginal buncher student with income $z^{*}+\triangle z$, representing the student with highest earnings in the absence of the notch who responds by locating below the income threshold.

Following Kleven and Waseem (2013), we calculate standard errors by using a residualbased bootstrap procedure. We generate a large number of income distributions by randomly resampling the residuals from equation (11) with replacement, and generate a large number of new estimates of the counterfactual density based on the resampled distributions. Based on the bootstrapped counterfactual densities, we evaluate variation in the bunching estimate. The standard error is defined as the standard deviation in the distribution of the estimate. 


\section{Bunching responses.}

We find clear local responses to the income threshold of the study subsidy program. Figure B1 presents the gross income distribution and the counterfactual distribution relative to the notch in bins of 100 euros in the range of $+/-6000$ euros from the notch in 1999-2013. The dashed vertical line denotes the notch point above which a student loses one month of the subsidy. The solid vertical lines denote the excluded range used in the estimation of the counterfactual, which is estimated using a 7th-order polynomial function. The dash-point vertical line above the notch shows the upper limit for the dominated region just above the notch where students can increase their net income by lowering their gross income subject to the income threshold.

Figure B1 indicates a visually clear and statistically significant excess mass $(2.19(0.189))$ below the income threshold for all students (standard error in parenthesis). This implies that students are both aware of the notch and respond to the strong local incentives created by it. In addition, there is clear evidence of the existence of some types of frictions. There is an economically and statistically significant mass of students, $0.915(.027)$ of the mass relative to the counterfactual, at the locally dominated region just above the notch where no students should locate in the absence of any types of frictions or constraints and when earnings choices are continuous (Kleven and Waseem 2013). Furthermore, even though the study subsidy schedule ultimately consists of multiple notches, we observe a distinctive response only to the first income threshold they face.

Figure B2 shows the bunching responses before (1999-2007) and after (2008-2013) the 2008 reform. The figure shows that excess bunching is slightly larger before $(2.55(0.228))$ than after $(1.71(0.882))$ the reform. One explanation for this is that the incentives not to exceed the notch are somewhat smaller after 2008, since the relative significance of losing one month's subsidy in terms of disposable income is now smaller than before 2008 when the threshold was at a lower income level. However, as discussed in Section 2 in the main text, this standard bunching method is not a valid measure for estimating labor supply responses to tax incentives under the discrete choice constraint, and therefore these estimates need to be interpreted as suggestive. 


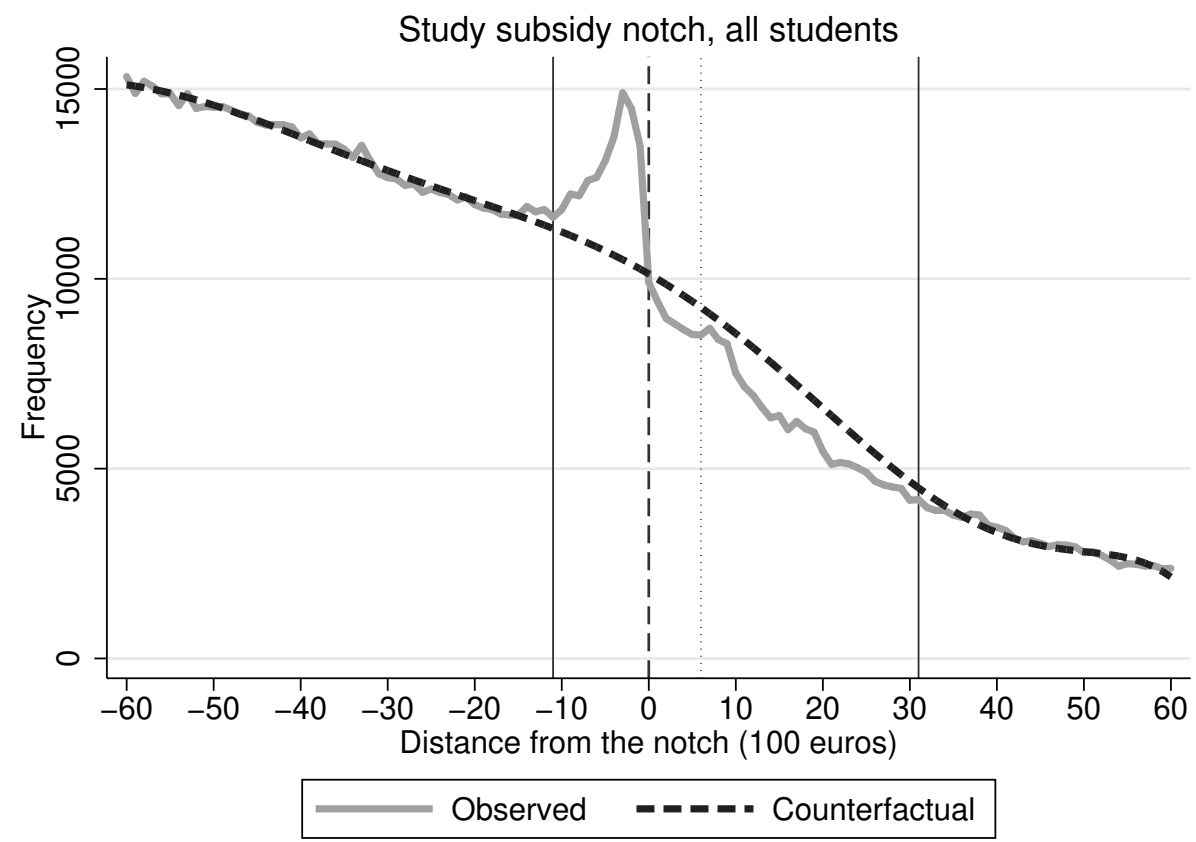

Notes: Figure presents the observed earnings distribution (gray solid line) and the estimated counterfactual distribution (black dashed line) around the income threshold (denoted by zero in the figure) in bins of 100 euros for all students using pooled data from 1999-2013. The first and second solid vertical lines denote the lower and upper limits of the excluded region when estimating the counterfactual distribution. The counterfactual is estimated using a seventh-order polynomial. The dotted vertical line denotes the upper limit of the region of dominated choice just above the threshold. The estimate for excess bunching at the notch is $2.19(0.189)$, and the estimate for the mass at the dominate region is $0.915(0.027)$.

Figure B1: Bunching at the study subsidy notch, 1999-2013 

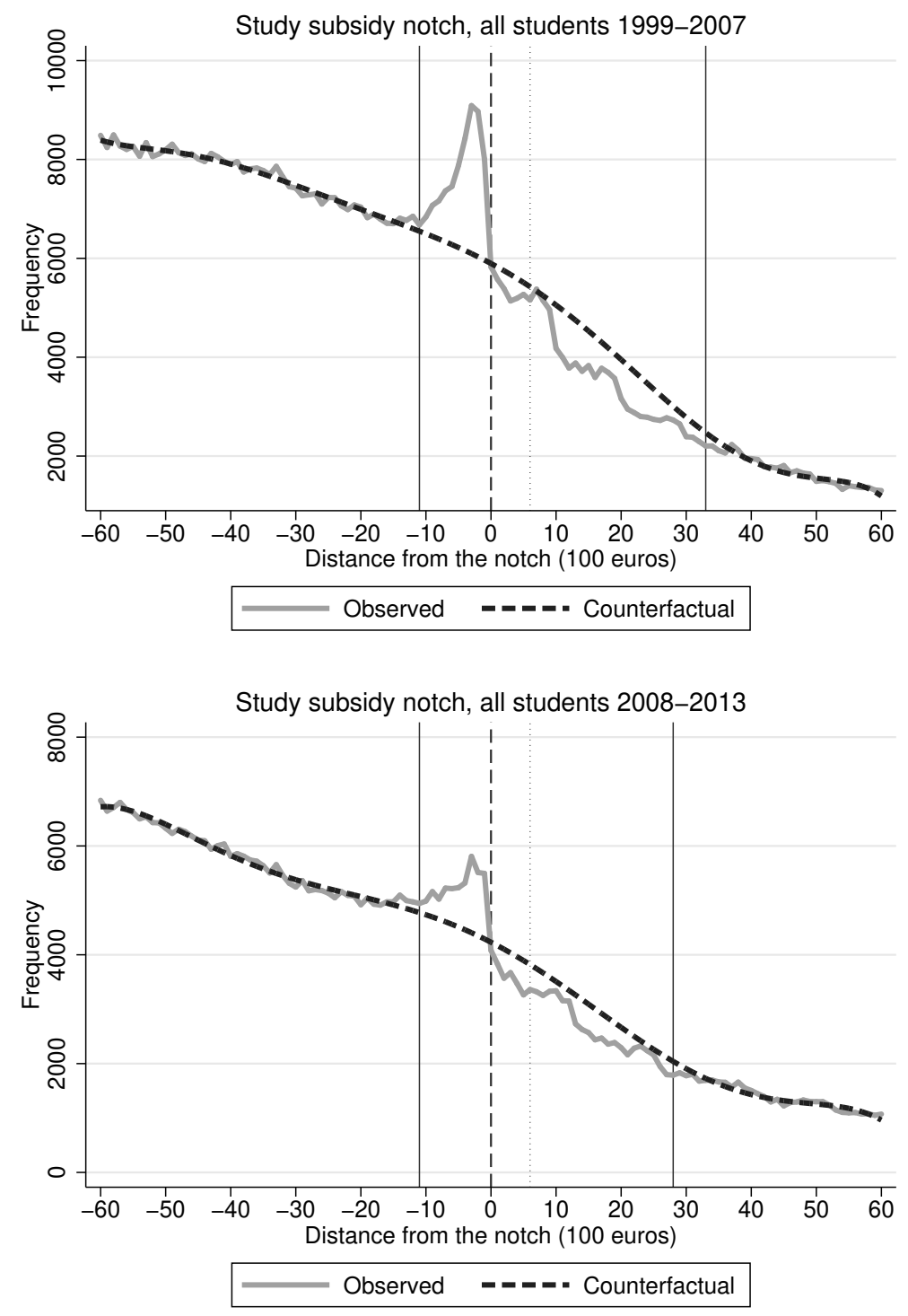

Notes: Figure presents the observed earnings distributions (gray solid line) and the estimated counterfactual distributions (black dashed line) around the income threshold (denoted by zero in the figure) in bins of 100 euros for all students before (1999-2007) and after (2008-2013) the 2008 threshold reform. The first and second solid vertical lines in the figure denote the lower and upper limits of the excluded region when estimating the counterfactual distribution. The counterfactual is estimated using a seventh-order polynomial. The dotted vertical line denotes the upper limit of the region of dominated choice just above the threshold. The estimate for excess bunching at the notch before 2008 is $2.55(0.228)$ and 1.71(0.882) after the reform.

Figure B2: Bunching at the study subsidy notch: Before and after the 2008 reform

\section{Earnings elasticity estimates.}

We approximate the earnings elasticity at the study subsidy notch using a similar approach as Kleven and Waseem (2013). We derive an upper-bound reduced-form earnings elasticity by relating the earnings response of a marginal buncher student at $z^{H}$ to the implicit change in tax liability between the notch point $z^{*}$ and $z^{H}$ (see Figure 2 in the main text). The marginal buncher represents the individual with the highest income to move to the notch point, compared to a counterfactual state in the absence of the notch. Intuitively, this approach treats the notch 
as a hypothetical kink which creates a jump in the implied marginal tax rate. More formally, the reduced-form earnings elasticity is calculated with a quadratic formula

$$
e\left(z^{*}\right) \approx\left(z^{H} / z^{*}\right)^{2} /(\triangle t /(1-t))
$$

where $(1-t)$ is the net-of-tax rate at the notch, and $\Delta t$ defines the change in the implied marginal tax rate for the marginal buncher (Kleven and Waseem 2013).

The implied earnings elasticities are $0.083(0.019)$ for all students and $0.065(0.007)$ for students with 9 subsidy months. Nevertheless, as discussed above, the bunching method does not capture all earnings responses when the earnings choices are discrete, and therefore these estimates do not represent the true earnings elasticity of students. 